This is the peer reviewed version of the following article:

De la Cruz Morales K., Alarcón-Angeles G., Merkoçi A.. Nanomaterial-based Sensors for the Study of DNA Interaction with drugs. Electroanalysis, (2019). . : - .

10.1002/ elan.201900286,

which has been published in final form at https://dx.doi.org/10.1002/elan.201900286. This article may be used for non-commercial purposes in accordance with Wiley Terms and Conditions for Use of Self-Archived Versions. 


\title{
Nanomaterial-based sensors for the study of DNA interaction with drugs
}

\author{
K. De la Cruz Morales ${ }^{\mathrm{a}}$, G. Alarcón-Angeles ${ }^{\mathrm{a}}$, A. Merkoçi ${ }^{\mathrm{b}, \mathrm{c} *}$ \\ a Universidad Autónoma Metropolitana-Xochimilco, Departamento de Sistemas Biológicos, C.P. 04960, D.F. México Affiliation \\ a \\ b Catalan Institute of Nanoscience and Nanotechnology (ICN2), CSIC and BIST, Campus UAB, Bellaterra, 08193 Barcelona, \\ Spain \\ c ICREA - Catalan Institution for Research and Advanced Studies, Barcelona, 08010, Spain \\ * arben.merkoci@icn2.cat
}

Received: ((will be filled in by the editorial staff))

Accepted: ((will be filled in by the editorial staff))

\begin{abstract}
The interaction of drugs with DNA has been searched thoroughly giving rise to an endless number of findings of undoubted importance, such as a prompt alert to harmful substances, ability to explain most of the biological mechanisms, or provision of important clues in targeted development of novel chemotherapeutics. The existence of some drugs that induce oxidative damage is an increasing point of concern as they can cause cellular death, aging, and are closely related to the development of many diseases. Because of a direct correlation between the response, strength/ nature of the interaction and the pharmaceutical action of DNA-targeted drugs, the electrochemical analysis is based on the signals of DNA before and after the interaction with the DNA-targeted drug. Nowadays, nanoscale materials are used extensively for offering fascinating characteristics that can be used in designing new strategies for drug-DNA interaction detection. This work presents a review of nanomaterials (NMs) for the study of drug-nucleic acid interaction. We summarize types of drug-DNA interactions, electroanalytical techniques for evidencing these interactions and quantification of drug and/or DNA monitoring.
\end{abstract}

Keywords: Nanomaterials, drug-DNA, Biosensing, DNA-electroanalysis, drug-DNA interaction.

DOI: 10.1002/elan.((will be filled in by the editorial staff))

\section{Introduction}

Deoxyribonucleic acid (DNA) represents one of the most important biomolecules because it contains all the genetical material that encodes the information necessary for the development of organisms with just four bases: adenine, guanine, cytosine, and thymine. The structure of DNA is arranged in so manner that bases are protected from chemical modification by the environment.

The hydrogen bonding resulting from the base pairing takes place at the center of the double helix while the characteristic negative-charged phosphate backbone is on the outside of the helix. On the outside of DNA, the spaces between the intertwined strands from two helical grooves of different widths are called the major groove and the minor groove. Hence, the detection of specific sequences, the base-pair composition or damage of DNA represents an important issue.

The interaction mechanism of drugs with DNA has been searched thoroughly during the past decades [1-4], giving rise to an endless number of findings of undoubted importance, such as a prompt alert to harmful substances, ability to explain most of the biological mechanisms, or provision of important clues in targeted development of novel chemotherapeutics $[5,6]$. The process of interaction involves small or large molecules that selectively recognize each other through different types of molecular interactions, i.e., electrostatic, dipole-dipole, hydrogen bonding, $\pi-\pi$, and van der Waals interactions. The strength of these interactions determines the stability of the resulting supramolecular complexes. The main chemical driving forces, for both the stability of double-stranded DNA (dsDNA) and DNA-drug recognition, are hydrogen bonding interactions, electrostatic and $\pi-\pi$ interactions between the aromatic rings of base pairs [3,7]. Furthermore, the existence of some drugs that induce oxidative damage is an increasing point of concern as they can cause cellular death, aging, and are closely related to the development of many diseases, such as arteriosclerosis, ischemia/reperfusion injury, hepatitis, Parkinson's and Alzheimer's diseases, rheumatoid arthritis, brain ischemia, stroke, and even carcinogenesis [8-11].

This work presents a review of nanomaterials for the study of drug-nucleic acid interaction. We summarize types of drug-DNA interactions, electroanalytical techniques for evidencing these interactions, as well as the 
use of nanomaterials in DNA biosensing and quantification of drug and/or DNA monitoring.

\subsection{DNA-drug interactions}

There are several types of interactions associated with ligands that bind DNA. These include intercalation, noncovalent groove binding, covalent binding/crosslinking, DNA cleavage, nucleoside-analog incorporation and oxidative damage [12]. Furthermore, several studies have reported mixed or more than one binding modes for various small molecules interacting with DNA. This property of mixed binding mode can be linked to their mechanism of action and therapeutic efficiency.

\subsubsection{Intercalation}

Intercalation is the most common mode of interaction by which small molecules may bind to DNA. Each drug has unique binding site preferences, for example, some prefer to intercalate between a 5'-purine-pyrimidine-3' base step rather than a 5'-pyrimidine-purine-3' base step (or vice versa), whereas others have no preference of order, but prefer certain base-pair sequences [13]. Intercalators, which contain planar heterocycle groups, can slide and stack between the base pairs of DNA and stabilize the duplex without disrupting base pairing or forming covalent bonds. Moreover, the intercalation of a drug lengthens, stiffens and unwinds double helix in DNA[5]. Examples of drugs that intercalate into DNA are acridine, anthracycline antibiotics, echinomycin [14].

\subsubsection{Groove binding}

Small molecules, which can bind to nucleic acid grooves, have the potential to achieve higher selectivity against desired targets compared to DNA intercalators [15]. The double-helix structure of DNA displays the major and minor grooves having different width and depth, and one end of the base pair is exposed to the major groove while the other is exposed to the minor groove [13]. Is reported that, "the interaction drug-DNA is the sum DNAintercalation and groove binding assisted by the formation of additional molecular interactions with the nucleobases" [16]. Drugs that bind to the minor groove are distamycin, esperamicin, chromomycin and mitracycin [17] (see Figure 1).

\subsubsection{External binding}

This kind of interaction occurs when some ligands are capable of forming electrostatic interactions with the negatively-charged nucleic sugar-phosphate structure in a non-specific manner $[12,18]$. As a result, the ligands selfassociate and stack on the anionic DNA backbone to reduce charge-charge repulsion between ligand molecules.

\subsubsection{Alkylators}

Alkylating agents are electrophilic enough to add methyl or other alkyl groups to DNA bases forming covalent adducts which are in fact irreversible [18]. These nucleophilic substitution reactions at the DNA bases occur by SN1 (nucleophilic substitution 1, the rate-determining step is unimolecular) and SN2 (nucleophilic substitution 2, the rate-determining step is bimolecular mechanisms. The most reactive sites in DNA are $\mathrm{N}(7)$ and $\mathrm{N}(3)$ in guanine and adenine, respectively, as both are nucleophilic and more exposed in the grooves of the DNA duplex [5]. DNA alkylating agents have played an important part in cancer chemotherapy since the introduction of nitrogen mustards more than fifty years ago. Examples of these drugs include bis(benzimidazoles), pyrrolizidines and pyrrolobenzodiazepines [19], see Figure 1.

\subsubsection{DNA cleavage}

Strand-breaking drugs induce DNA cleavage when the covalent sugar-phosphate linkage between nucleotides is cut. Cleavage may be exonucleolytic, removing the end nucleotide, or endonucleotide, splitting the strand in two $[5,13]$. Bleomycines are probably the most representative antibiotics of this category since their discovery in 1966; enediyne antibiotics, such as calicheamicins, esperamicins and neocarzinostatins, can cleave double-stranded DNA as well [13].

\subsubsection{Oxidative damage}

Drug-induced oxidative stress is considered a drug-related side effect and is implicated as a mechanism of toxicity in many tissues and organ systems. The extent to which mechanisms of drug-induced oxidative stress have been characterized varies [10]. Oxidation of nucleic acids belongs to one of the most common damages to DNA. Oxidative damage occurs through the formation of radicals and not radical species, such as ROS (reactive oxygen species), nitrogen (RNS), or sulfur (RSS) species. To date, more than 20 modifications to purine bases, which are the most easily oxidized, have been described [20]. Drugs that induce oxidative damage include anthracyclines, analgesics such as paracetamol, and antibiotics such as albendazole [21-23]. 


\section{Review}

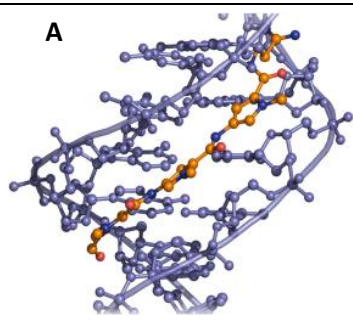

C

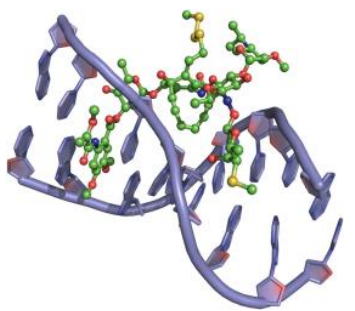

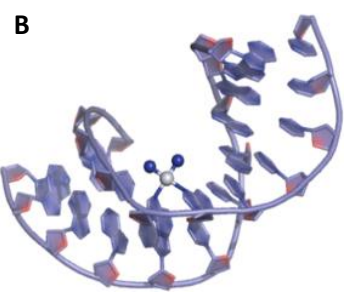

D

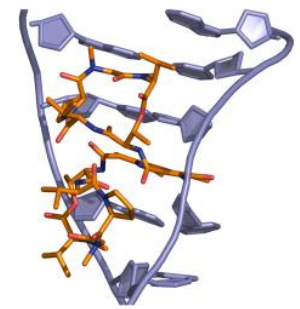

Fig. 1. DNA binding view from the three-dimensional structure of different complexes of the drug, A: Distamicyn-DNA duplex in the minor Groove. B. Actinomycin-DNA duplex. C. Esperamicin A1-DNA duplex, in the minor Groove of doublestranded. D. Cisplatin-DNA intra-strand adduct. From reference [5] with permission from Elsevier.

\section{Electroanalytical techniques used to evidence drug- DNA interactions}

Currently, there is a wide variety of strategies devoted to depicting drug-DNA interactions, which will continue to grow. Techniques range from the classic UV-Vis (UltraViolet-Visible) spectrophotometry to the powerful tandem HPLC-MS. Needless to say, there is an urgent need for rapid, high throughput, continuous, and costeffective techniques for analysis of the interaction between genes, proteins, and drugs to speed up drug discovery and drug approval processes. It is particularly true for high throughput screening of trace molecules and natural products, where the amount of model DNA and/or drug might be low or limited to weak absorption spectra, the overlap of electronic transition with that of DNA or weak or no absorption spectra [24].

Electrochemistry is one of the most affordable techniques that has gained popularity over the last decades as it provides a useful complement to the standard methods of investigation. Electrochemical methods are based on changes in the current and potential peak in a voltammogram (as a result of the change in the formal potential or the change in the electron transfer rate) that can be attributed to the interaction among the species surrounding the electrode $[2,6,12]$. Information that can be provided based on the analysis of the current peaks and potential include evidence for the interaction mechanism, nature of the redox species formed, binding constant and

size of the binding sites [16]. It should also be possible to obtain kinetic data from current and potential measurements [18].

In recent years, much progress has been achieved in understanding the electrochemical and interfacial behaviors of nucleic acids (NAs) at electrodes, to the extent that researchers can now fine-tune the NA surface state and electrical properties at an almost atomic level [25]. Electrochemical methods are well suited for DNA analysis/diagnostics because electrochemical reactions give an electronic signal directly, so there is no need for expensive signal transduction equipment. Moreover, because immobilized probe sequences can be readily confined to a variety of electrode substrates, detection can be accomplished with an inexpensive electrochemical analyzer. Sensitive electrochemical signaling strategies, based on the direct or catalyzed oxidation of DNA bases, as well as the redox reactions of reporter molecules or enzymes recruited to the electrode surface by specific DNA probe target interactions and by charge transport reactions mediated by the $\pi$-stacked base pairs, have all been demonstrated [26].

Electrochemical methods can be used for the detection of: (a) DNA strand breaks and base damage; and (b) electroactive substances that specifically interact with DNA (covalently and/or noncovalently) [27].

\subsection{Electrochemical detection}

Since the electroactivity of purine and pyrimidine bases was found by Emil Palecek in 1958, working procedures utilize this special detection principle. Bases have electroactive properties, and they can be reduced and/or oxidized; other components of nucleic acids such as sugar and phosphate groups are electroinactive. All common nucleobases are known to undergo electrochemical oxidation at carbon electrodes, and protonation of base residues is involved in the electrode process. Electrochemical analysis of the DNA can, thus, be performed without introducing labels into the DNA recognition element (label-free techniques) and even without introducing any additional reagent into the measuring system (reagent-less techniques)[28]. Nevertheless, the electrochemical reduction and oxidation of nucleobases are irreversible and thus do not allow reusability of biosensors because of the destruction of the sample. The vast majority of label-free DNA biosensors employ oxidation of guanine. This choice is dictated by (a) the relatively low redox potential of guanine and (b) the fact that guanine is the most frequent target for many DNA damaging species and its chemical modification is often accompanied by a loss of the guanine peak [29]. 


\subsubsection{Voltammetry}

Voltammetric -especially cyclic voltammetry (CV), differential pulse voltammetry (DPV), and square wave voltammetry (SWV) - and chronopotentiometric (CP) techniques are the most frequently used detection modes. Together with them, electrochemical impedance spectroscopy (EIS) is becoming popular in DNA-based biosensors.

Cyclic voltammetry is the most widely used technique for acquiring qualitative information about electrochemical reactions. The power of cyclic voltammetry results from its ability to rapidly provide considerable information on the thermodynamics of the redox process, on the kinetics of the heterogeneous electron-transfer reactions and coupled chemical reactions or adsorption processes. Cyclic voltammetry consists of scanning linearly the potential of a stationary working electrode (in an unstirred solution) using a triangular potential waveform. During the potential sweep, the potentiostat measures the current resulting from the applied potential [30].

$\mathrm{CV}$ is widely used for the evaluation of mode of action and binding strength of drug-DNA interaction. The peak potential and peak current of the compound change in the presence of DNA if the compound interacts with it. The variation in the peak current can be exploited for the determination of binding constant and binding size, whereas the shift in peak potential can be used to ascertain the mode of interaction $(18,31)$. Drugs that have been studied using $\mathrm{CV}$ and related techniques are nogalamycin, efavirenz, flutamide, anthracyclines, cisplatin, etopside and nevirapine [32-37].

On the other hand, differential-pulse voltammetry is an extremely useful technique for measurement of trace levels of organic and inorganic species. In differentialpulse voltammetry, fixed magnitude pulses, superimposed on a linear potential ramp, are applied to the working electrode at a time just before the end of the drop. The first current is instrumentally subtracted from the second, and this current difference is plotted versus the applied potential. The differential pulse operation results in a very effective correction of the charging background current [30]. DPV is probably the most used voltammetric technique in drug-DNA interactions as it achieves high sensitivity. The analysis in DPV is quite similar to CV; changes in the current peak and potential are parameters that are associated with the event. Examples of drugs that have been tested to interact with DNA using DPV are topotecan, codeine, gemcitabine, dextromethorphan and dacarbazine [38-42].
However, Square Wave Voltammetry is considered as one of the most advanced voltammetric techniques, which unifies the advantages of pulse techniques (enhanced sensitivity), cyclic voltammetry (insight into the electrode mechanism) and impedance techniques (kinetic information of very fast electrode processes)[43]. The analysis in DPV is quite similar to CV and DPV, where changes in the current peak and potential are parameters that are associated with the event. Drugs such as wedelolactone, 6-thioguanine or oxidative damage induced to DNA have been probed by using SWV $[44,45]$.

\subsubsection{Electrochemical Impedance Spectroscopy (EIS)}

The impedance measurement of the electrical interfaces has been widely used in recent years for investigation of the interactions of nucleic acids and their components with the electrode surface. This technique offers several advantages over chronoamperometry and cyclic voltammetry because the effects of solution resistance, double layer charging, and currents due to diffusion or to other processes occurring in the monolayer, are observed more explicitly. Electrochemical impedance spectroscopy (EIS) technique can provide information on the impedance changes before and after the biointeraction process at the electrode surface, which is mainly based on the change of the charge transfer resistance using a redox couple $[46,47]$. The EIS experiment is conducted using a sinusoidal electrochemical perturbation (potential or current) to the sample that covers a wide range of frequencies. Therefore, EIS allows the measurement of several electrochemical reactions that take place at very different rates and provides a more thorough understanding of an electrochemical system than any other electrochemical technique $[48,49]$. According to previous studies, EIS has been successfully applied for the detection of the interaction of topotecan, fluorouracil, benzaldehyde, and doxorubicin with DNA [50-53].

\subsection{Voltammetric parameters involved in drug-DNA interaction}

There is a direct correlation between the response, strength/ nature of the interaction and the pharmaceutical action of the DNA targeted drugs. The electrochemical analysis is based on the signals of DNA before and after the interaction with the DNA-targeted drug. The changes in the signals of an electroactive drug before and after the interaction with DNA also give an idea about what happens when these two molecules interact in the solution or at the surface $[2,6,12]$. The principle is based on the fact that the electrode detects the change in the DNA molecule. When an interaction occurs, changes in the current and 
position of the voltammogram are visible for both DNA and drug (as long as the molecule is electroactive), because of the altered availability of its electroactive sites. If modification of electroactive base residues occurs, their intrinsic oxidation may be lost or may also be improved because of perturbations in the dsDNA structure. Some products of DNA base damage or bulky electroactive DNA adducts yield new electrochemical signals not observed in the unmodified DNA. This is the case of one of the most abundant products of oxidative DNA damage, 8-oxoguanine, having lower redox potential than guanine, see Figure 2A. Formation of noncovalent DNA complexes with small molecules can in principle be detected via changes in electrochemical behavior of both the binders and the DNA. Upon binding to large molecules of DNA, apparent diffusion coefficients of the binder decrease, and altered mass transport of these species influences its electrochemical signals [54]. Peak potentials of the binders may also be changed upon the complex formation, depending on the binding mode (see Figure 2B). Different binding modes, specifically influenced by their electrochemical signals, are manifested by either positive (for intercalative binding) or negative potential shifts (in the case of primarily electrostatic interaction) [5], see Figure 2C. Interactions of intercalators or cationic groove binders with the DNA recognition layer result in accumulation of these substances at the DNA-modified electrode leading to enhancement of the binder electrochemical signals. This structure selectivity of some electroactive noncovalent or covalent DNA binders can be utilized in redox marker-based methods of electrochemical DNA structural probing. The redox indicators usually show their electrochemical response at potentials different enough from the nucleobases, which is often reversible. Some of the indicators interact with DNA through electrostatic forces, while others are present "free" in the solution phase. Special kind of redox indicators are the intercalators. Due to the accumulation within the immobilized dsDNA layer, the bound indicator exhibits an increased voltammetric response. Commonly, redoxindicator drugs are anticancer agents [55].
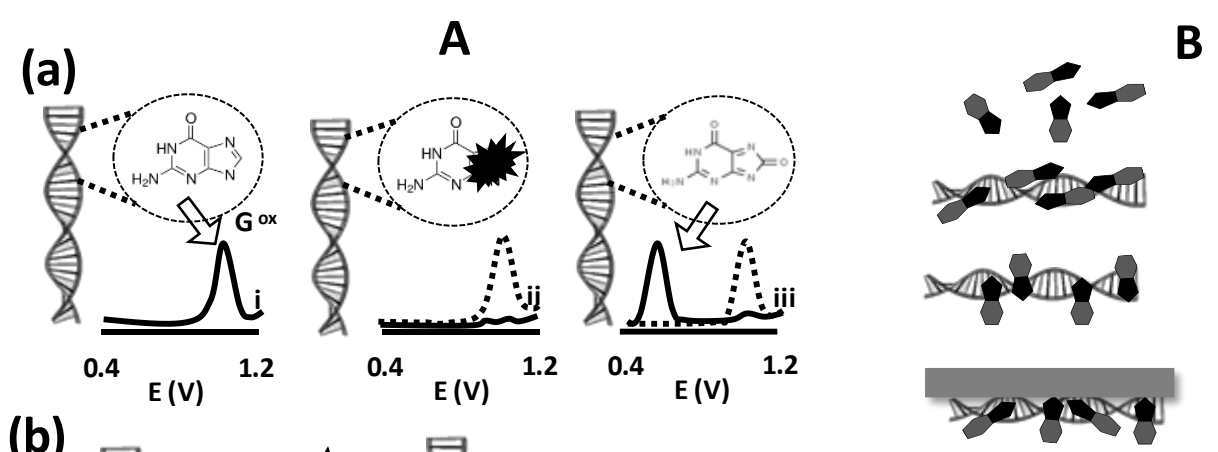

B
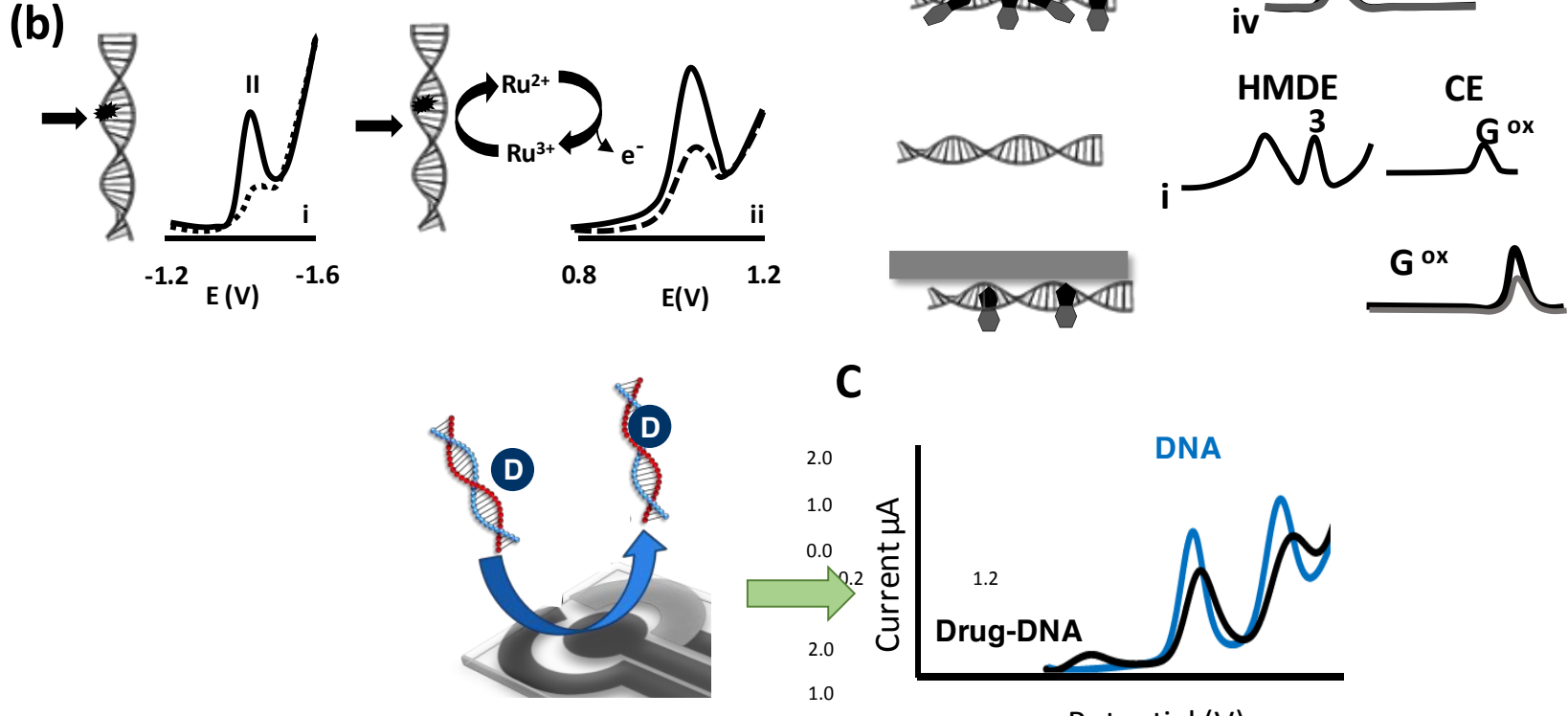

C

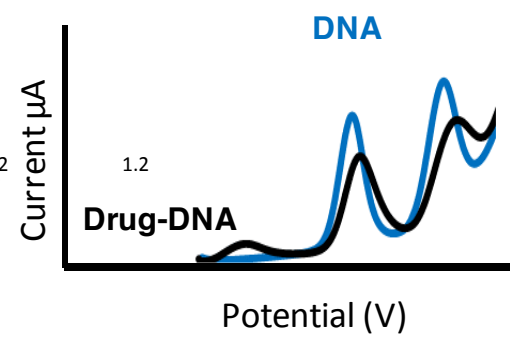

Fig. 2. A. Principles of electrochemical detection of covalent DNA damages. (a) Chemical modification of nucleobases ). (b) Base lesions. B. Principles of electrochemical detection of noncovalent DNA interactions with small molecules C. Schematic representation of the change in the intercalator redox signal derived upon the interaction with DNA. From references [54] with permission from Wiley. 


\subsection{The approach of the drug-DNA interaction}

Different electrochemical approaches have been carried out for the analysis of nucleic acids after the discovery of nucleic acid electroactivity at the beginning of the 1960s. Direct DNA electrochemistry, DNA specific redox reporter electrochemistry, electrochemical amplifications using nanoparticles, polymer-modified electrodes, etc. are different approaches that have been developed for the electrochemical DNA detection [56,57]. The highly specific molecular recognition ability of complementary nucleic base pairs has been widely applied in the design of various sensing systems for the detection of target nucleic acids $[58,59]$. For drug-DNA interactions, there are three main ways in which these studies can be performed.

\subsubsection{Interaction in the solution}

For detection of interaction in the solution, drug and DNA are placed in the same solution, and after some given time of interaction, the changes in the electrochemical signals of anticancer drug-DNA complex are compared to the signal obtained with DNA or drug alone [60].

\subsubsection{DNA adsorbed on the working electrode}

The immobilization of biomolecules via supramolecular or coordinative interactions has achieved wide acceptance in recent years in binding biological species to surfaces. These two approaches, related to electrostatic interaction, $\pi-\pi$ stacking, entrapment in polymers, or van der Waals forces between the nanomaterial and the biological entity, preserve all specific properties of both. It is because nanomaterials have the ability to reduce the distance between the redox site of immobilized protein or DNA and the working electrode surface since the rate of electron transfer is inversely dependent on the exponential distance between them [59].

Invention of Adsorptive Transfer Stripping (AdTS) voltammetry of DNA (based on DNA immobilization/ adsorption onto the electrode surface followed by medium exchange and measurement in a blank background electrolyte) was the first step toward the development of electrochemical DNA biosensors. Upon exposure of the sensor to different chemical or physical agents (including species causing DNA damage or otherwise interacting with the anchored DNA molecules), changes in the anchored DNA recognition layer may take place, which can subsequently be electrochemically detected.
To prepare the drug-modified electrode, the targeted drug is immobilized on the electrode surface. The main requirement for this strategy is the electroactivity of the drug so that the electrochemical signals of the drug can be monitored and then the changes in these signals after interaction with DNA can be observed [60].

Bulk electrodes with millimeter dimensions such as gold (Au), Glassy Carbon Electrode (GCE), carbon paste, were early used for implementation in bioanalysis; to date, they are still widely used for the initial development of assays, including DNA-drug interaction, primarily due to the ease of their preparation and functionalization. Progressively, smaller microscale electrodes were developed, and it was noted that these devices displayed unusual kinetic behavior when redox reactions were monitored in solution. Subsequently, it was discovered that ultramicroelectrodes strongly benefited from radial diffusion and in this manner enhanced electrochemical reaction kinetics. Encouraged by these results, the pace of research into new electrode materials increased rapidly, and the use of microelectrodes was recognized as an important advance [62].

\section{Nanomaterials}

Nowadays it is recognized that nanomaterials have been produced and used by humans for hundreds of years. However, the understanding of certain materials as nanostructured materials is relatively recent. The multidisciplinary nature of nanotechnology is the distinguishing characteristic of this technology, in the manner that it has a notable impact on different areas including health, energy, environment in addition to other industries. Publication of nanotechnology research and review articles has increased in the previous years, and the number of groups and laboratories engaged in the study of fundamental science, engineering and applications of nanostructured materials has grown almost exponentially [63-67].

A nanomaterial (NM) can be defined as a material having at least one characteristic length scale in the 1-100 $\mathrm{nm}$ range, and with at least one property being considerably different from that of the bulk counterpart, as a result of the nanoscale dimensions (68-70). Nanomaterials (NMs) can also be larger objects that contain nanoscale structures, either internally or on their surfaces (nanostructured materials), see Figure 4.

\subsection{Classification}


The concept of dimensionality is very useful in the classification of nanomaterials. According to Siegel, nanostructured materials are categorized based on their dimensionality. Zero-dimensional (0-D) nanomaterials are smaller than $100 \mathrm{~nm}$ in all directions (e.g., nanoparticles, nanopores), while one-dimensional (1-D) nanomaterials are smaller than $100 \mathrm{~nm}$ in 2 directions only (e.g., nanorods, nanowires, nanotubes), and two-dimensional (2D) nanomaterials are smaller than $100 \mathrm{~nm}$ only in the thickness direction (e.g., thin films, nanoplates). However, one should keep in mind that the critical length scale is not necessarily $100 \mathrm{~nm}$, as it depends on the material and property under consideration $[67,68,69,71,72]$. For carbon atoms, the main representative materials according to this classification are: buckyballs (linear or 0-D), nanotubes (1-D), graphene (plane or 2-D), and diamond and graphite (tetrahedral or 3-D), [72-74], see Figure 3.

Nanoparticles (NPs) and nanoscale materials (NSMs) can also be classified as natural or synthetic, based on their origin. Natural nanomaterials are produced in nature either by biological species or through anthropogenic activities. The production of artificial surfaces with exclusive micro and nanoscale templates and properties for technological applications are readily available from natural sources $(70,75,76)$. Synthetic (engineered) nanomaterials are produced by several methods including mechanical grinding, engine exhaust, and smoke, or are synthesized by physical, chemical, biological or hybrid methods $[67,70]$.

Morphological characteristics to be considered include flatness, sphericity, and aspect ratio, which divide them in low and high aspect ratio particles. The high aspect ratio nanoparticles involve nanowires, nanohelices, nanozigzags, nanopillars, nanotubes, or nanobelts. The low aspect ratio nanoparticles are spherical, helical, pillarlike, pyramidal, and cubic, among others [64,70,71,77], see Figure 3A.

According to their uniformity, nanoparticles can be classified as isometric and inhomogeneous. From the point of view of their agglomeration status, nanoparticles can be dispersed or agglomerated. Their agglomeration state depends on their electromagnetic properties, such as surface charge and magnetism [78]. When in a liquid, their agglomeration depends on their surface morphology and functionalization which can confer them either hydrophobicity or hydrophilicity $[79,80]$, see Figure $3 \mathrm{~A}$.

Nanoparticles can be made of a single material, compact or hollow. Nanomaterials can also be comprised of two or more materials and exist like coatings, encapsulated, barcode, or mixed. Most current NPs and NSMs can be organized into four material-based categories: carbonbased nanomaterials, inorganic-based nanomaterials, organic-based nanomaterials and composite-based nanomaterials [81,82], see Figure 3Aa.
A

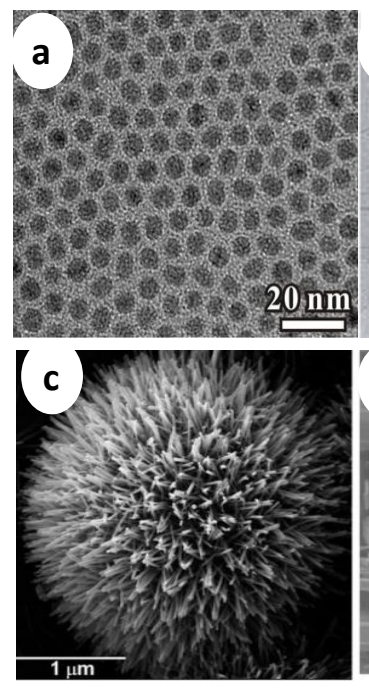

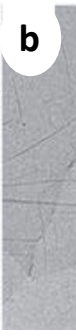

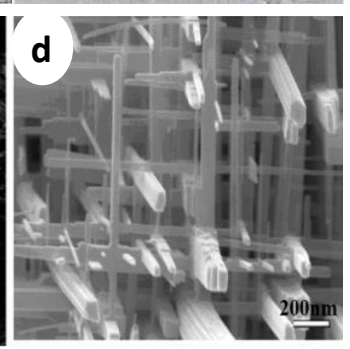

B

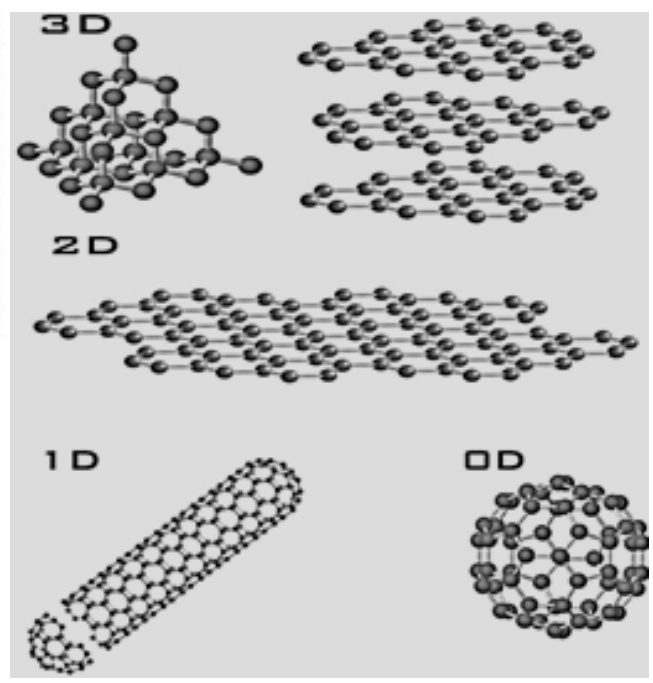

Fig. 3., A. Nanomaterials with different morphologies: (a) nonporous Pd NPs (0D) (b) Graphene nanosheets (2D) From reference $[64,72]$ with permission from Springer Nature Publishing, (c) urchin-like ZnO nanowires (3D) From reference [75] with permission from Wiley, (d) $\mathrm{WO}_{3}$ nanowire network (3D), From reference [76] with permission from Wiley. B. Crystal structures of different allotropes of carbon. (Left to right) Diamond and Graphite (3D); Graphene (2D); Nanotubes (1D); and Buckyballs (0D). From references [71] with permission from Elsevier. 


\subsection{Nanomaterials properties}

Similar to quantum mechanisms, on the nanometer scale, materials or structures may possess new physical properties or exhibit new physical phenomena not seen in their bulk components. Such differences may include altered chemical or biological activity; increased structural integrity; or altered electrical, optical, or magnetic properties [84].

The most obvious effect associated with the reduction of scale is the much larger specific surface area or surface area per unit mass. Surface atoms are less stable than bulk atoms, which means that the surface of nanomaterials is more reactive than their bulk counterparts [85]. As the size of particles decreases towards the molecular level, their behavior is more like that of a vapor; as a consequence, nanometer size particles will have much higher mobility than particles in the micrometer scale [77]. Nanomaterials may have a significantly lower melting point or phase transition temperature and appreciably reduced lattice constants, due to a huge fraction of surface atoms in the total amount of atoms. Another property that NMs possess is related to the gravitational settling velocity which is proportional to their diameter. As a result, nanoparticles suspended in the atmosphere may be deposited onto surfaces much more slowly than larger particles. Indeed, deposition of nanoparticles will be independent of orientation and will occur as they become trapped in the boundary layer on all surfaces [77]. NMs tend to the aggregation due to their specific surface area and volume effects. One of the most fascinating and useful aspects of nanomaterials is their optical properties. The optical properties of nanomaterials depend on parameters such as feature size, shape, surface characteristics, and other variables including doping and interaction with the surrounding environment or other nanostructures. Likewise, the shape can have a dramatic influence on the optical properties of metal nanostructures [86]. Mechanical properties of nanomaterials may reach the theoretical strength, which is one or two orders of magnitude higher than that of single crystals in the bulk form. The enhancement in mechanical strength is simply a result of the reduced probability of defects. Electrical conductivity decreases with a reduced dimension due to increased surface scattering. However, the electrical conductivity of nanomaterials could also be enhanced appreciably due to the better ordering in the microstructure. Magnetic properties of nanostructured materials are distinctly different from those of bulk materials. Ferromagnetism of bulk materials disappears and transfers to superparamagnetism in the nanometer scale due to the huge surface energy. Self-purification is an intrinsic thermodynamic property of nanostructures and nanomaterials. Any heat treatment increases the diffusion of impurities, intrinsic structural defects, and dislocations, and one can easily push them to the nearby surface. Increased perfection would have a visible impact on the chemical and physical properties [82].

\subsection{Nanomaterials in DNA biosensing}

Nanomaterials are being explored for applications in different disciplines including physics, medicine, biomedicine, and chemistry to develop miniaturized devices [87-91]. By realizing the extraordinary properties of nanomaterials such as their high surface area, tuning property in optical emission, electrical and magnetic properties, etc., these can be exploited in bioengineering ranging from drug delivery to biosensors [75,92-94]. The intelligent use of such nano-objects led to clearly enhanced performances with increased sensitivities and lowered detection limits of several orders of magnitude.

In recent years, nucleic acids have been extensively used into a wide range of biosensors and bioanalytical assays, due to their wide range of physical, chemical and biological activities and tremendous molecular recognition potential $[95,96]$. Functionally, integrating DNA and other nucleic acids with nanoparticles in all their different physicochemical forms has produced a rich variety of hybrid bio-nanocomposites which, in many cases, display unique or augmented properties due to the synergistic activity of both components [97].

\subsection{Interactions DNA-nanomaterials}

\subsubsection{Carbon based}

Carbon has long been applied as an electrochemical sensing interface owing to its versatility and unique electrochemical properties. Procedures in electroanalysis strongly depend on material aspects such as chemical and physical properties of electrode surfaces, the effects of the applied potential, adsorption, and coatings applied to the electrode surface to enhance detection [72,73], see Figure 4A. Carbon-based nanostructures, such as carbon nanofibers, carbon nanotubes, and mesoporous carbons, have been extensively used in the fabrication of modified electrodes for applications in both analytical and industrial electrochemistry. In addition to their low price, they exhibit suitable electrocatalytic activity for a variety of redox reactions, a broad potential window, and relatively inert electrochemistry [98]. 
Carbon nanotubes (CNTs) are certainly the most studied nanomaterials ever, considering the cumulated number of papers devoted to them since the 1990s. Because of their reactivity properties, carbon nanotubes may also exhibit strong interactions with biological systems [99]. CNTs have a large surface area, small diameter, and high curvature, which allow them to effectively interact with biomolecules through van der Waals, $\pi-\pi$ stacking and hydrophobic interactions [100], see Figure 4B. These properties can also be used to facilitate the surface modification of CNTs to increase their solubility in aqueous media or modulate the covalent attachment of functional groups for biomedical application [101,102].

Recently, graphene has attracted wide research interest because of its superior electrical conductivity and excellent mechanical strength $[103,104]$. Since its discovery, graphene oxide (GO) has been used for adsorbing many biomolecules because of its substantial surface-to-volume ratio to interface with biomolecules, especially DNA [105,106], see Figure 5C. GO is a loosely defined material, and the oxygen content can vary quite a lot depending on the preparation conditions [107]. The adsorption affinity of DNA is likely to depend on the oxygen content. Another related material is called reduced GO (rGO), which is prepared by chemically reducing GO to decrease its oxygen content. GO has poor electrical conductivity due to its extensively disrupted $\pi$ - $\pi$ conjugation system; however, rGO has an intermediate conductivity and still retains the ability to disperse in water $[61,108]$.

\subsubsection{Nanoparticles-based}

The excellent conductivity, high surface area, and catalytic and redox properties make $\mathrm{Au}$ nanoparticles excellent material for electrochemical labels in nucleic acid detection, with numerous configurations being explored; they provide an efficient tool for immobilizing DNA on electrodes as well as a label to signal the hybridization event $[109,110]$. The functionalization of AuNPs is generally done through the $\mathrm{Au}-\mathrm{S}$ bond, using biomolecules modified with thiol groups [111]. Applications of nanoparticles in electrochemical signal amplification are mainly based on two types of mechanism: 1) nanoparticles that increase the loading of the electrochemically detectable species since every nanoparticle contains thousands of atoms that can be electrochemically detected and 2) nanoparticles that catalyze the electrolysis of a large quantity of substrate, which enhances the electrochemical signal [112]. The strategies that utilize nanoparticle labels in electrochemical affinity biosensors can be sub-categorized into 4 main types, sorted in ascending order of complexity: nanoparticles that increase the loading of electroactive species; nanoparticles that act as ultramicroelectrode arrays for the electrolysis of large amounts of substrate; nanoparticles that are used as catalysts to deposit electrochemically detectable species; and nanoparticles that mediate the deposition of electrocatalysts [113]. Currently, many DNA sensing systems have been integrated with Au NPs to enhance the detection limit and sensitivity [114].

Electron transport properties of nanowires are very important for electrical and electronic applications as well as for understanding the unique one-dimensional carrier transport mechanism. It has been noticed that the wire diameter, wire surface condition, crystal structure and its quality, chemical composition, crystallographic orientation along the wire axis, etc., are important parameters, all of which influence the electron transport mechanism of nanowires. Biological macromolecules, such as proteins and nucleic acids, are typically charged in aqueous solution and, as such, can be detected readily by nanowire sensors when appropriate receptors are linked to the nanowire active surface. Silicon nanowires and DNA modified gold nanowires have been used to construct DNA sensors [115]. The improved sensitivity attributed to these materials strongly suggests that the threedimensional architectures of the nanowires facilitate the electrocatalytic reaction because of enhanced diffusion occurring around these structures. It means that unique effects at the nanoscale underlie the utility of nanowires for DNA biosensing [116,117].

Nanocomposites usually refer to dispersion-type coatings wherein one of the components is nanosized but remains dispersed in a matrix [118]. Nanocomposites properties are determined by component properties, composition, structure, and interfacial interactions as a result of improvement in the sensitivity and LOD (lower limit of detection). Nanocomposites have also been investigated as a means to create a suitable microenvironment for the stabilization of biomolecules [119].

The association of nanomaterials such as noble metal nanoparticles with graphene sheets has become a hot topic and achieved remarkable results. The graphene nanocomposites have been tested very widely [120]. Decoration of graphene by other carbon nanomaterials has given rise to new physical properties through cooperative and synergetic effects, and the functionalized composites have found more applications in electrochemical sensing fields where they were previously less competitive [121]. Metal NP/ graphene nanocomposites can not only act as excellent electrochemical sensing materials but also 
provide an ideal matrix for the immobilization of enzyme and DNA, enabling the design of highly selective and sensitive electrochemical biosensors. Metaloporphyrins and metalphthalocyanines (MPcs) can noncovalently bind to graphene via strong $\pi$-interactions offering stable, functional matrixes, used in DNA sensing [122]. Polymers such as chitosan form nanocomposites with graphene oxide, carbon nanotubes and AuNPs and have been employed for the development of DNA based electrochemical biosensor for diagnosis [123-125].

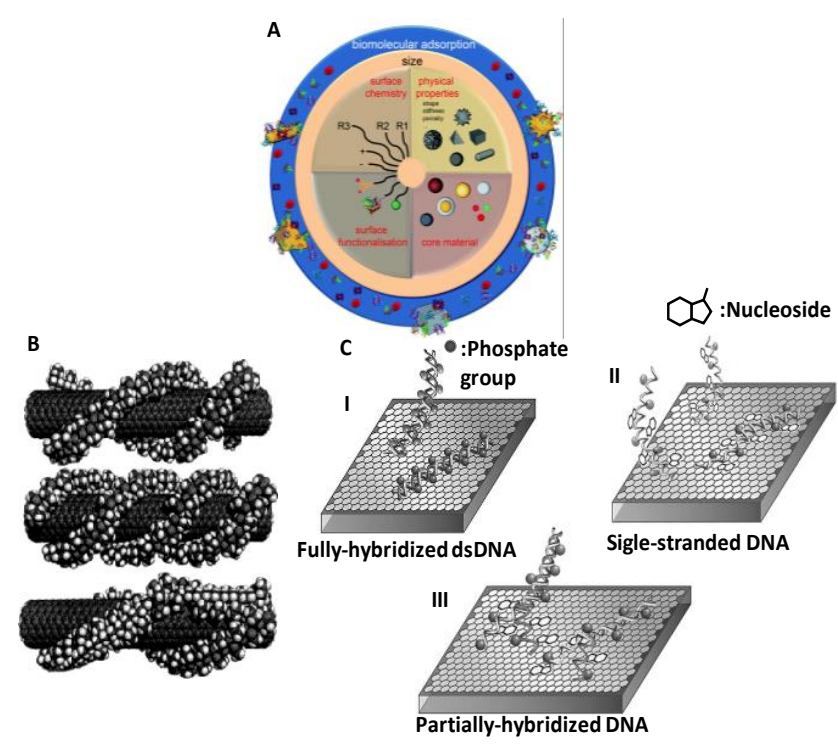

Fig. 4.A. Schematic illustration. A. The multitude of possibilities in terms of the combination of physical properties, surface chemistry, and functionalization which will be further modified by the biological environment From references [79] with permission from The Royal Society of Chemistry. B. The model of DNA interaction with CNT. C. The interaction between graphene and (I) fully hybridized dsDNA, (II) ssDNA (single stranded DNA), and (III) partially hybridized DNA. From references $[126,127]$ with permission from Elsevier.

\subsection{Analysis of the drug-DNA interaction using nanomaterials}

In recent years, nanoscale materials are used extensively for offering fascinating characteristics which can be used in designing new strategies for drug-DNA interaction detection. These nanoparticles provide the researchers with more efficient techniques for interfacing DNA recognition with electrochemical signal transduction. The recent electrochemical drug-DNA binding studies based on nanomaterials are summarized in Table 1; the types of drugs that have been analyzed are anticancer agents antibiotics, antihistaminic, antivirals, nonsteroidal antiinflammatory drugs, neurotransmitters, vitamins and retroviral [3,4,128-173]. Upon discovery of the advantages that nanomaterials could bring to analytical science, the first researches regarding the DNA-drug interaction were done in solution. Later, more sophisticated methods making use of complex architectures and immobilization techniques to construct DNA biosensors were reported (Table 1 y 2). Furthermore, these biosensors showed clinical application to be used in the detection of drugs in biological matrixes.

In 2006, Zhongze Gu et al. [128] reported a new nanocomposite produced by the combination of (polylactide) PLA nanofibers, fabricated by electrospinning, with titanium dioxide $\left(\mathrm{TiO}_{2}\right)$ nanoparticles. They found that the combination could facilitate the interaction of daunorubicin with DNA in solution better than those with free nanocomposites or just nano $\mathrm{TiO}_{2}$ or PLA nanofibers so that much more significant decrease in the peak current occurs when both nanomaterials are applied. This observation suggests the efficient accumulation or self-assembly of daunorubicin and/or DNA molecules on the nanoscaled surface of the new nano $\mathrm{TiO}_{2}$-PLA polymer nanocomposites due to the relatively large surface area and unique properties of this new blending nanocomposites.

Similarly, in 2007, Wang et al. [129] explored the utilization of nano-titanium dioxide $\mathrm{TiO}_{2} / \mathrm{GCE}$ modified electrodes to enhance the detection of doxorubicin and its biorecognition by DNA in solution upon applying UV irradiation. They explained that under UV irradiation, some active radicals, such as hydrogen peroxide, hydroxyl radicals, and other ROS (Reactive Oxigen Species), are generated in such a manner that they could approach the doxorubicin and make the oxidation of doxorubicin easier. As such, more doxorubicin molecules could be readily self-assembled onto the surface of the nano-TiO2modified electrode through electrostatic interaction, see Figure 5A. Moreover, they carried out experiments where they found that the surface of the electrode became much more hydrophilic after the UV, while the corresponding change of contact angle values of doxorubicin takes place in the presence of DNA.

\subsubsection{Analysis of the drug-DNA interaction in a DNA biosensor}

One general advantage of all nanomaterials is that the high specific surface enables the immobilization of an enhanced amount of biomolecule units [73,99,130-133]. However, one of the constant challenges is the immobilization strategy used to conjugate the bio-specific entity intimately on such nanomaterials. Since most of the 
nanoparticles carry charges, they can electrostatically adsorb biomolecules with different charges.

Since 1991, carbon nanotubes (CNTs) have received great attention due to their outstanding properties; however, they still surprise us with their unlimited applications in different disciplines. In 2012, Brahman and colleagues [137] designed an MWCNT (Multiwalled Carbon Nanotubes) paste electrode and developed a method which served to monitor the interaction of the fluoroquinolone antibiotic, gatifloxacin (GTF) with DNA, in solution and on DNA modified electrode. They successfully constructed a DNA biosensor and found that GTF is oxidized at both electrodes, but the peak current decreases and peak potential shifts to more positive values at the DNA-modified electrode in comparison with the bare electrode. Furthermore, they constructed a pharmacosensor by modifying the working electrode with GTF that allowed monitoring the decrement in the current of guanine and adenine. The analysis of the interaction was also made in solution, and the determination of the constant binding and the ratio of the complex formed was achieved using CV. The applicability of the proposed method was further extended to in vitro determination of the drug in biological fluids such as serum, plasma, and urine with DPV.

Primo et al. in 2014 [155], reported a study that represents a new alternative to build supramolecular architectures for biosensing. A GCE modified with bamboo-like multi-walled carbon nanotubes (bCNT) dispersed in double-stranded calf-thymus DNA (dsDNA), showed bioaffinity properties of the dsDNA that supports the bCNT at GCE/bCNTdsDNA towards promethazine (PMZ), despite the drastic conditions for preparing the dispersion of bCNT in dsDNA. After comparing dsDNA and ssDNA, an increment in the oxidation current of PMZ about 19.7 times higher than at GCE and considerably higher than the one obtained at GCE/bCNT-ssDNA was observed. To demonstrate the nature of the interactions, the effect of the ionic strength was evaluated; the results showed a decrease in the current peak of the drug upon addition of $\mathrm{NaCl}$ evidencing that the main interaction mode between PMZ and ssDNA was electrostatic, see Table 2. They suggested that although electrostatics plays some role in the interaction between PMZ and bCNTdsDNA due to the presence of the phosphate groups, in the case of dsDNA van der Waals interactions between the DNA bases and PMZ, independent of the salt concentration of the medium, are the main factors responsible for the PMZ oxidation current. They demonstrated that PMZ could be accumulated not only due to the adsorptive effect of bCNTs but also to the preconcentration mainly by intercalation within the double helix of the dsDNA that supports the bCNTs, making possible the sensitive quantification of PMZ.

Bagheryan et al. in 2016 [169], reported a screen-printed graphite electrode (SPE) modified with synthesized SBAN-propylpipyrazine-N-(2-mercaptopropane-1-one) (SBANPPNSH) mesoporous structure to investigate the $G$ quadruplex DNA (G4DNA) formation and stabilization. Human telomeric DNA typically consists of many tandem repeats of the guanine-rich sequences d(TTAGGG) termed an intermolecular G-quadruplex structure (Table 1). Telomeres are highly repetitive sequences at the end of chromosomes that are essential for genome stability. This structure plays an important role in the protection, stabilization, and replication of chromosome ends and is thereby an active target for therapeutic purposes. It is plausible that G-quadruplex structures in certain regions of the genome also contribute to the inhibition of the activity of telomerase, a cancer-specific reverse transcriptase that is activated in $80-90 \%$ of tumors. It has been reported that small molecules targeting the G-quadruplex structure through various binding modes can inhibit telomerase activity and interfere with telomere extension by blocking the elongation step catalyzed by telomerase. In this regard, choosing a ligand with a good affinity with G-quadruplex to either stabilize this structure or induce the folding of this single-stranded DNA is a good strategy for cancer therapy, as it could be a potential anticancer agent.

Differential pulse voltammetry was used to examine the stability and formation of G4DNA in the presence of positive and negative G4DNA binding ligands (Table 1). After the addition of ligand, another oxidation peak was observed and increased by increasing ligand concentration at $\mathrm{Epa}=1.044$ and $1.094 \mathrm{~V}$ due to the oxidation of guanine in the G-quadruplex, with similar results to those observed in the presence of $\mathrm{K}+$. In the second phase of the study, the competition of the complementary strand of the Gquadruplex structure with the drug TMPyP4, for binding to G-quadruplex was investigated in the presence and absence of $\mathrm{K}+$ ion concentration. This study revealed that after adding $\mathrm{K}+$ or positive G4DNA-binding ligand, a new peak was observed in higher potential due to oxidation of guanine residuals in the G-quadruplex structure. This data revealed interesting information about the stabilization of the ligand and the G-quadruplex: 1) TMPyP4 has stabilized G-quadruplex structure and interacted with it in a good manner, 2) the ligand can also induce the complementary strand to form the G4DNA structure and so reduce the stability of dsDNA, 3) the formation of the G-quadruplex structure is stabilized by $\mathrm{K}+$ cations as observed in the DPV signals by the appearance of a new oxidation peak in higher potential due to resistance to oxidation. Furthermore, the described method provides a 
simple way for selecting a $G$ quadruplex-binding ligand and can be used for selecting antitumor ligands and therapeutic agents.

\subsubsection{Analysis of the drug-DNA interaction in a pharmacosensor}

In 2018, Shervedani et al. [167] published an interesting paper as a prove concept, where they reported the preparation of a pharmacosensor by immobilizing methotrexate (MTX) anticancer drug in three different ways: a) covalent bonding using EDC/NHS as the organic activators to form the amide bond, b) electrografting of MTX diazonium salt and c) noncovalent bonding, being electrografting the best method to immobilize the drug. To evaluate the interaction ability of the immobilized MTX with biological species they used calf thymus DNA (ctDNA), mouse 4T1 breast tumor and Human foreskin fibroblast (hFF) cells as models of the primary intracellular target of anticancer drugs, for cancer and normal cells, respectively. The interaction of MTX with DNA was performed using DPV by means of the decrease in the current peak of the drug, which is electroactive. Further information about the nature of the interaction was achieved with UV-Vis, which were electrostatic. Interaction of GC-GNs-MTX(ER) and GC-GNs/MTX systems with $4 \mathrm{~T} 1$ cancer cells and hFF cells was traced by EIS; the Rct was increased by a factor of $\sim 4.5$ and 5.3 upon incubation. The authors concluded that the system showed a high affinity of the constructed systems for 4T1 cancer cells.

\subsection{Quantification of drug and/or DNA monitoring}

Using the drug-DNA interaction, useful analytical information can be obtained from the increased DNA (guanine) response, in a manner that one can determine several drugs concentration using an electrochemical approach in complex biological matrices [47,60, 134-164].

Widely used anti-cancer treatments involving chemotherapeutic drugs result in cancer cell damage due to their strong interaction with DNA and monitoring of the drug concentration in biological fluids is important as many side effects are related to this kind of compounds. Laboratory biosensors used for screening chemotherapeutic drugs and the assessment of DNA modification/damage caused by these drugs are currently being developed (see Table 2). In 2018, Hatamluyi et al. [151], constructed a biosensor made of polyamidoamine (PAMAM) dendrimer/reduced graphene oxide nanocomposite, using a modified pencil graphite electrode (PAMAM/RGO/PGE) for determination of Rituxan at low concentrations, see Figure 5B. In this study, they optimized the conditions to favor the interaction of the drug and took advantage of the linear decrease in the oxidation peak current of guanine with the increase in Rituxan to quantify the drug in human serum samples. Furthermore, they calculated the binding constant of the Rituxan-DNA complex. In a similar study, Karimi-Maleh et al. [156] used didanosine as a drug model to probe that the DNA biosensor fabricated by using a pencil graphite electrode modified with conductive materials such as polypyrrole (PPy) and reduced graphene oxide (rGO) (PGE/PPy/rGO), see Figure 5C. Then, the interaction of the drug with DNA was identified through decreases in the oxidation currents of guanine and adenine by differential pulse voltammetric (DPV) method. However, the main purpose of the novel biosensor was the measurement of didanosine in real samples. According to the obtained data, the detection limit was found to be lower than in HPLC. Another example was proposed by Ilkhani et al. [146], who monitored the doxorubicin-DNA reactivity with a self-assembled monolayer protected gold-disk electrode (AuDE); this electrode was coated with a reduced graphene oxide (rGO) and decorated with plasmonic goldcoated $\mathrm{Fe}_{2} \mathrm{Ni} @$ Au magnetic nanoparticles, functionalized with a sequence of the breast cancer gene BRCA1, see Figure 5D. They found differences in the electrochemical signals of a redox probe $\left(\mathrm{Fe}^{2+}\right)$, attributed to the intercalation of doxorubicin with DNA using $\mathrm{CV}$ and DPV, see Figure 5E 


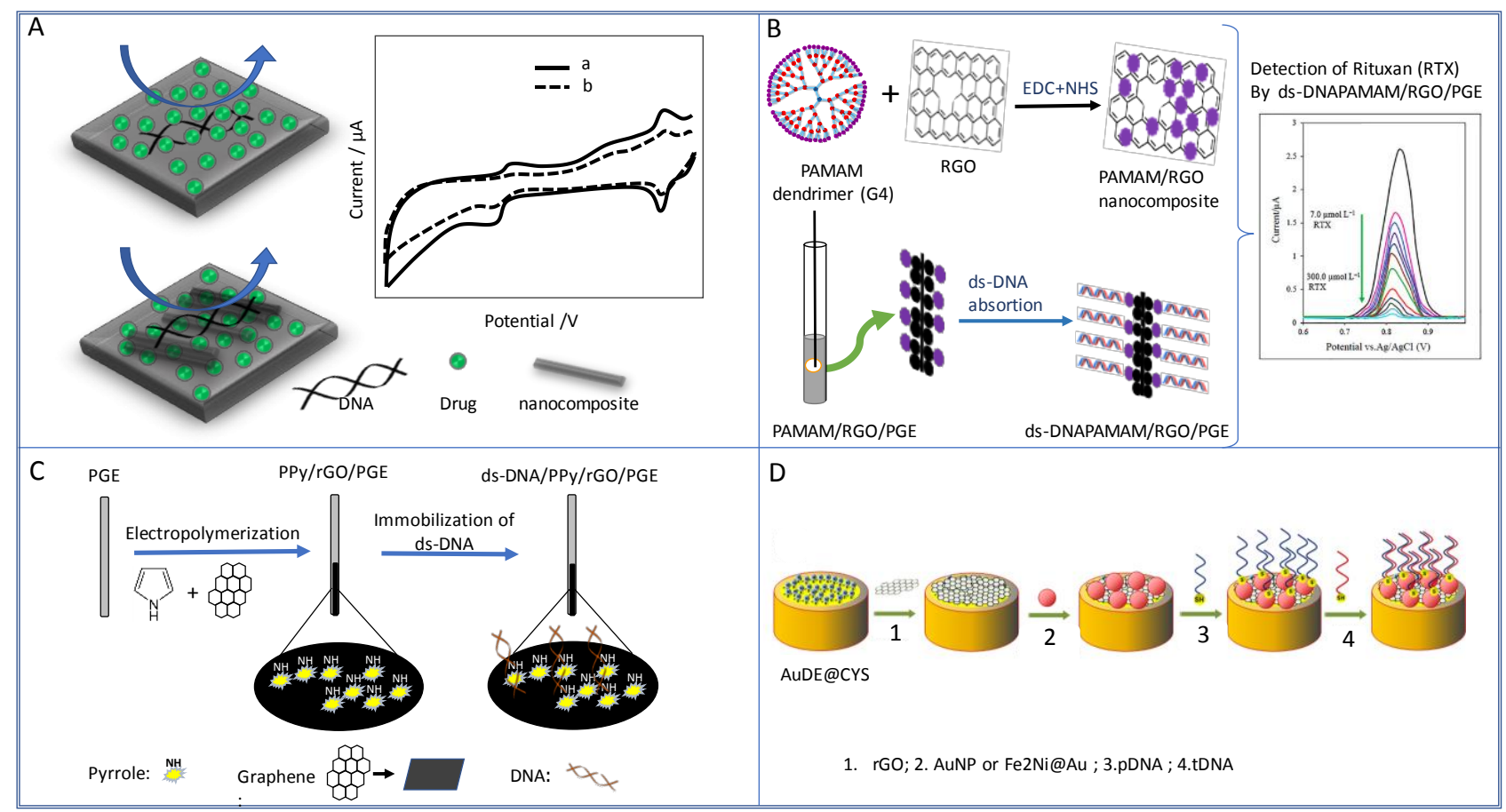

Fig. 5. Schematic representation of biosensors used to detect DNA-drug interaction A. Electrochemical detection of daunorubicin binding to DNA at GCE (I) in the absence and (II) presence of the blends of nano $\mathrm{TiO}_{2}$ and PLA nanofibers. B. Fabrication of dsDNA/PAMAM/RGO/PGE biosensor and the detection of Rituxan. From references $[128,138]$ with permission from Wiley. C. Surface amplification of pencil graphite electrode with polypyrrole and reduced graphene oxide for fabrication of a guanine/adenine DNA based electrochemical biosensors for determination of didanosine anticancer drug E. Construction of SERS/electrochemical nanobiosensor for testing doxorubicin interactions with DNA: gold disk electrode (AuDE) substrate protected with a Self-assembled monolaye (SAM) of cysteamine (CYS) and reduced graphene oxide (rGO) with covalently attached AuNPs or Fe 2 Ni@Au NPs functionalized with dsDNA. From references $[139,146]$ with permission from Elsevier 
In 2011, Elahi et al. [161] constructed a biosensor based on the physisorption of dsDNA on a polypyrrole nanofiber (PPyox) film that was electrochemically deposited onto a Pt electrode. Then the interaction of DNA with salicylic acid (SA) and acetylsalicylic acid (ASA) was studied on the electrode surface with DPV. Binding of DNA to the Ptmodified working electrode occurred because of the electrostatic attraction of the delocalized positive charges of the oxidized polymer and the negative charges of DNA phosphate groups. The guanine oxidation currents from the DNA/PPyox electrode decreased upon the addition of SA and ASA and over time, indicating the interaction of DNA with both drugs. A linear relationship was observed between the decrease in the current of guanine oxidation and the concentration of both drugs.

They found interesting data with regard to the affinity of the drugs for DNA: a) the slope of the ASA reaction is smaller than that of the SA reaction, and the peak current of guanine oxidation vanished and diminished to zero, faster for the SA-DNA complex than for the ASA-DNA complex, indicating faster interaction kinetics of SA compared to ASA with DNA, b) SA interacts at lower concentrations compared with ASA, c) the binding constant, $\mathrm{Kd}$, of SA for DNA was higher than ASA. Finally, from the comparison of the structures of SA and ASA, they hypothesized that the salicylate backbone plays an important role in the DNA-ligand interaction, suggesting that the presence of an extra acetyl group in ASA causes a slower interaction that may be due to steric hindrance of the acetyl group in the binding of salicylate backbone to the minor groove.

Wei et al. in 2012 [163], investigated the interaction of diclofenac with DNA and took advantage of this to construct a graphene-based biosensor to monitor photodegradation $\left(\mathrm{UV} / \mathrm{H}_{2} \mathrm{O}_{2}\right)$ of the drug. Diclofenac, as a typical emerging pharmaceutical contaminant in the environment, has been the focus of many reports. Upon increasing the concentration of diclofenac, they found that the peak current of DNA-GO/GCE decreased, while the peak potential shifted positively. It means that it could be attributed to the fact that diclofenac intercalated between the base pairs of DNA inhibiting the electrochemical oxidation of DNA on the electrode (see Table 1 and 2). The peak current of guanine was found to linearly decrease with the increase of diclofenac concentration; this behavior was useful to evaluate the applicability of the DNA-GO/GCE biosensor as an analytical tool. The response of the sensor to photodegraded diclofenac was the increase in the current peak of guanine with prolonged degradation time, indicating that diclofenac was degraded by the $\mathrm{UV} / \mathrm{H}_{2} \mathrm{O}_{2}$ process. The result also implied that the genotoxicity of diclofenac was reduced after photodegradation.

Lin et al. in 2017 [134] provided a method to prepare a modified glassy carbon electrode (GCE) using reduced graphene oxide-Nafion and dsDNA in order to produce a dsDNA/RGO-Nafion/GCE sensor to quantify Clenbuterol (CLB), b2 agonist typically employed in bronchial treatment, especially for the therapy of chronic illnesses. It is illegally added to the feed for pigs and cattle to improve the yield of lean animals in some developing countries as a kind of adrenal neural stimulant that promotes protein synthesis, which can accelerate the transformation and decomposition of fat. The dsDNA/RGO-Nafion/GCE produced more intense DPV peak currents for both guanine and adenine. The experimental results showed that the anodic peak currents of both guanine and adenine decreased with the increase in immersion time and their anodic peak potentials shifted negatively. They suggested that the electrochemical oxidation product of CLB is positively charged and interacts very readily with the negatively charged phosphonic groups of the backbone of DNA. The dsDNA was surrounded by the oxidation product of CLB with a positive charge, so a decline of the oxidation peak currents for guanine and adenine was detected. It was found that there is a proportional relationship between the decrease in the anodic peak currents of the adenine and the concentration of added CLB, thus providing a good method to determine CLB indirectly (Table 2).

Tahernejad-Javazmi et al. in 2018 [144] reported the construction of a biosensor by the modification of GCE with $\mathrm{Au}-\mathrm{NPs} / \mathrm{rGO} / \mathrm{dsDNA}$ to monitor the interaction of dasatinib with DNA and its determination in biological matrixes. They found that the guanine oxidation peak current decreased in the presence of dasatinib and the oxidation peak potential shifted to more positive potentials due to intercalation of this anticancer drug in major or minor grooves of DNA. Also, they figured it out that this reduction in current could be selected as a suitable factor relative to the concentration of dasatinib in the solution and saw that the biosensor was suitable for analysis of dasatinib in tablet and urine samples by the standard addition method.

Furthermore, they found that the temperature has an important effect on the reaction speed. The guanine signal reduces by moving the temperature from $10{ }^{\circ} \mathrm{C}$ towards $25{ }^{\circ} \mathrm{C}$ due to the faster movement of dasatinib towards AuNPs/rGO/GC surface and better interaction with dsDNA. Further increase in temperature (to $30^{\circ} \mathrm{C}$ ) was not suitable because a weak interaction between dsDNA and dasatinib was detected. Finally, the binding constant was calculated (Table 2). 


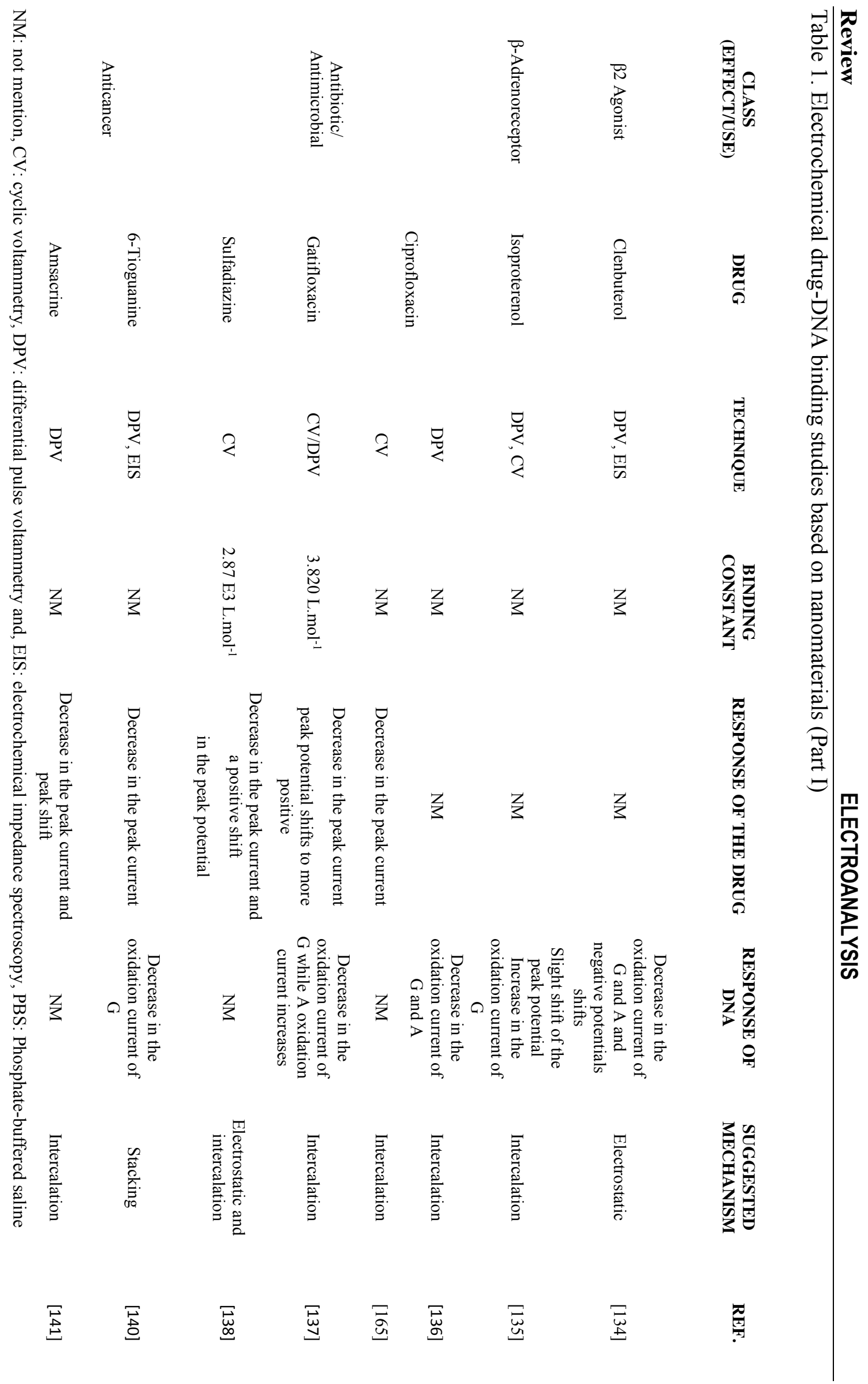




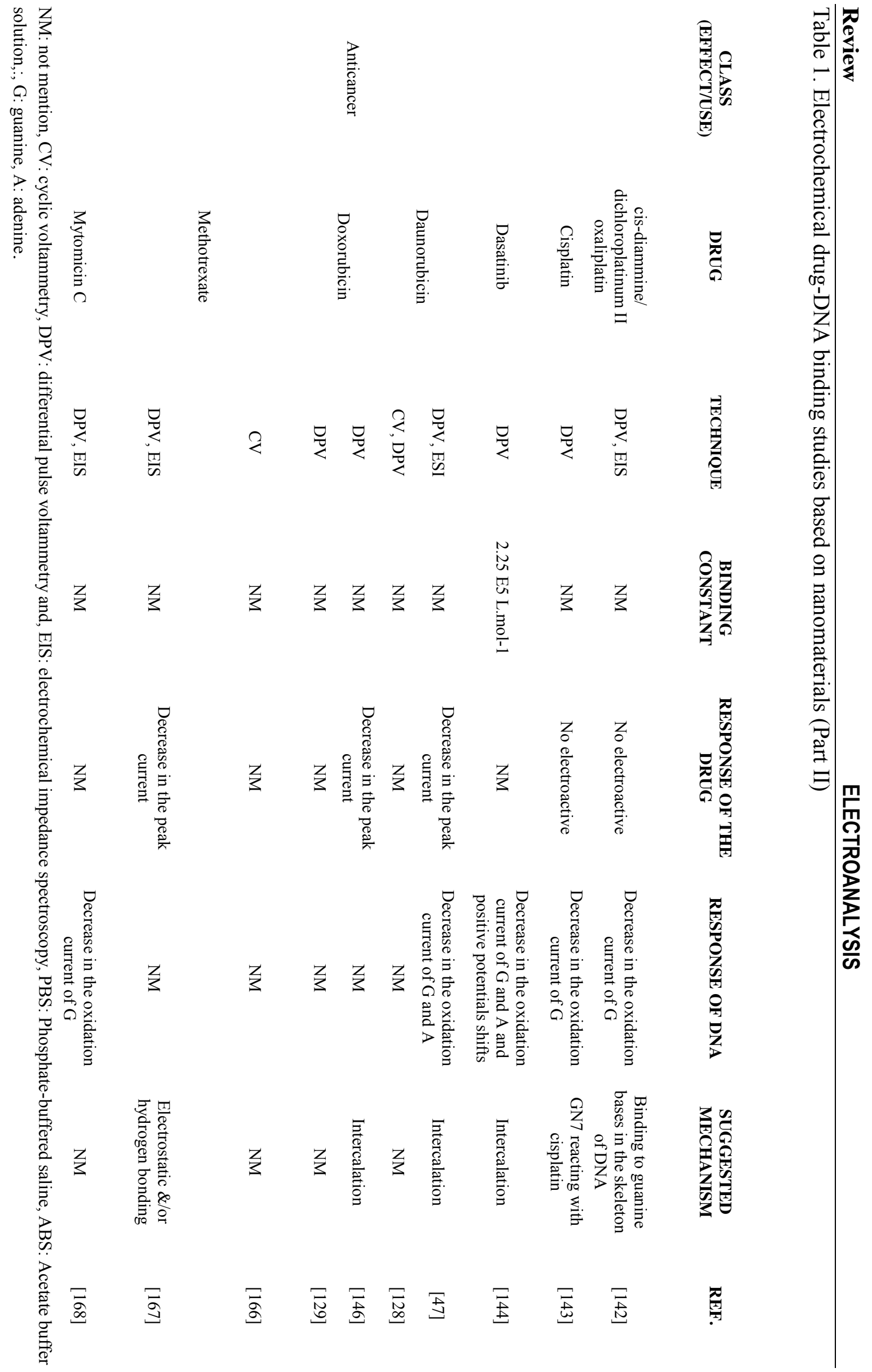




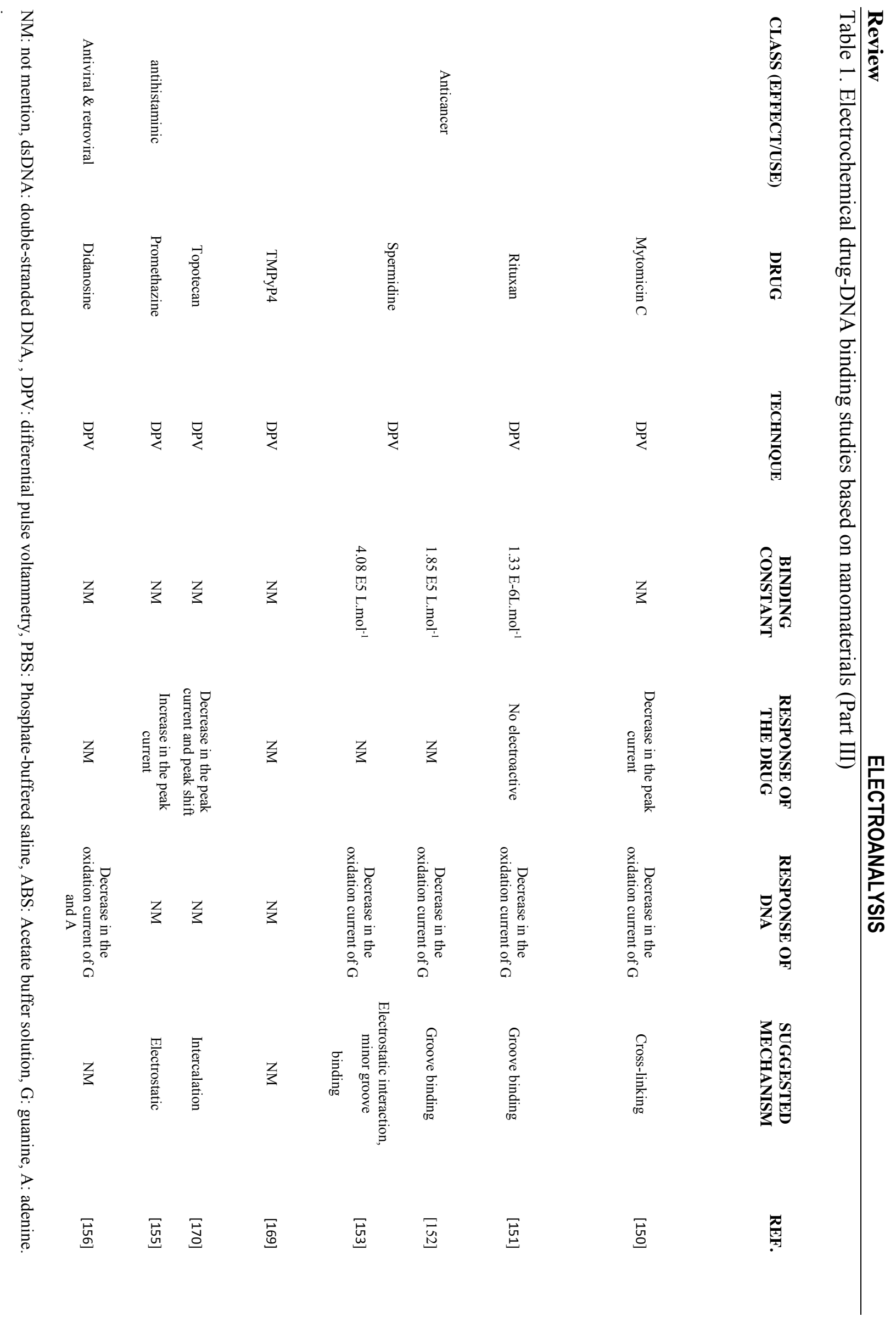




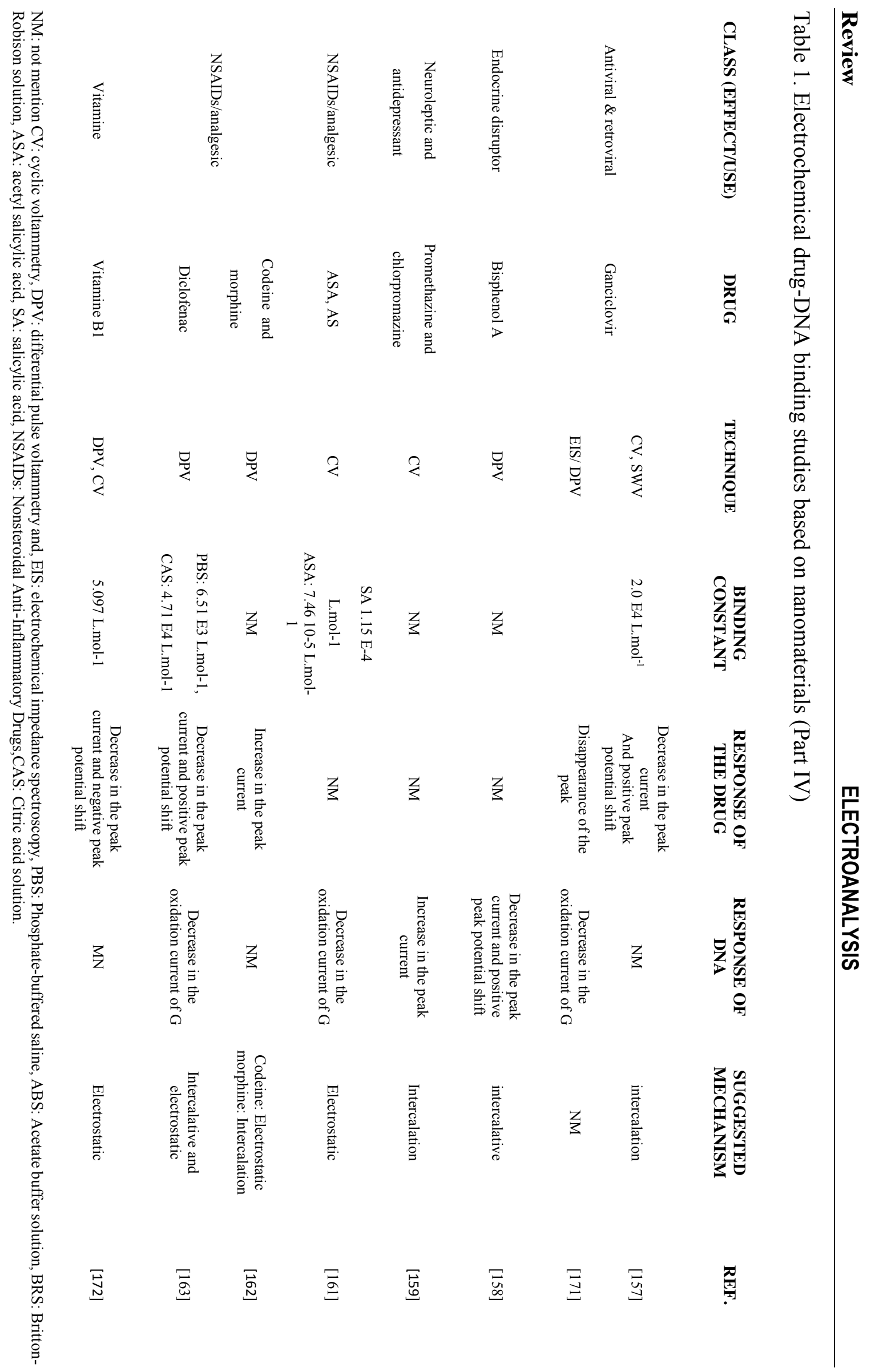




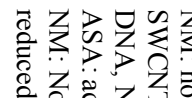

范

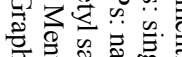

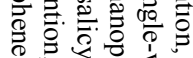

ํ. कै.

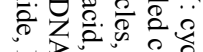

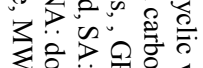

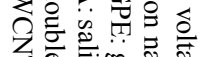

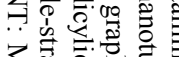

言

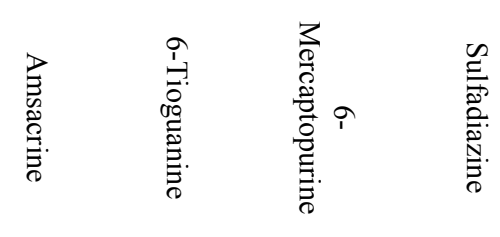

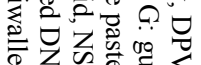

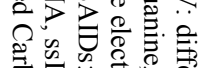

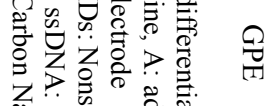

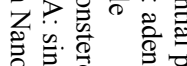

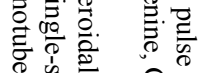

की ति

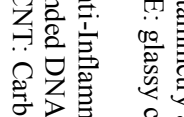

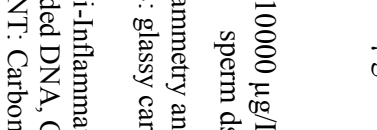

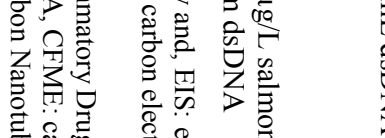

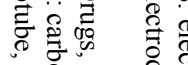

औद

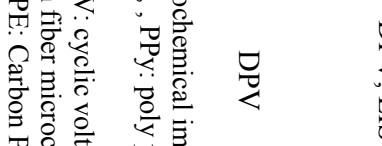

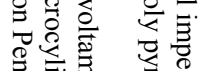

节.

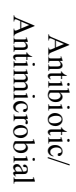

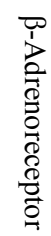

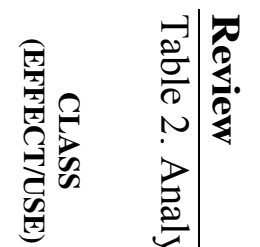

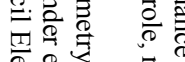

응

के

究

कृष

䓀

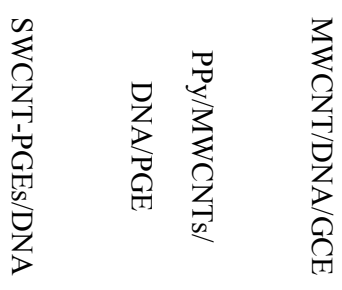

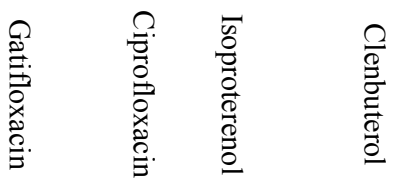

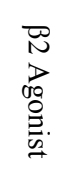

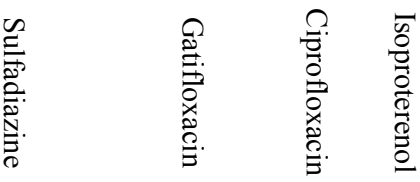

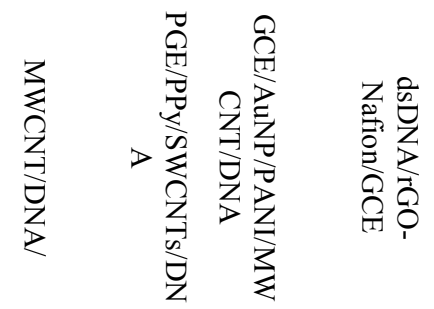

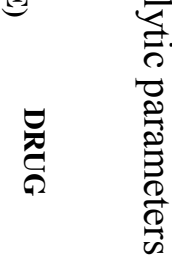

远

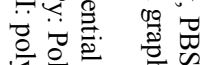

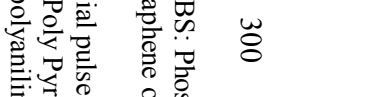

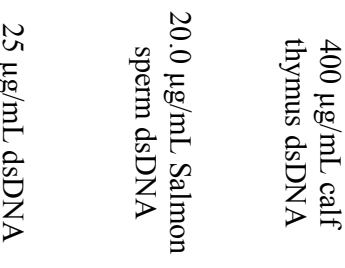

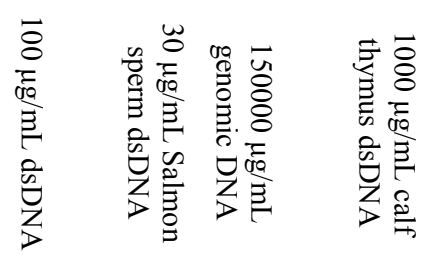

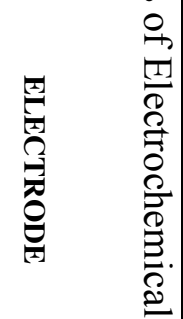

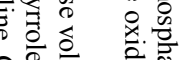

तิ

ㅁำ

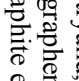

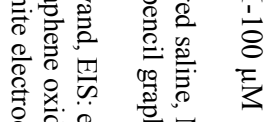

के $\frac{0}{2} \frac{0}{2}$ है

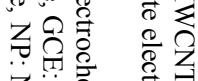

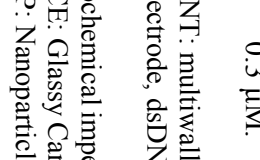

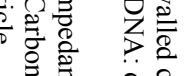

0
$\dot{1}$
$\vdots$
3
$\vdots$
8
3
3

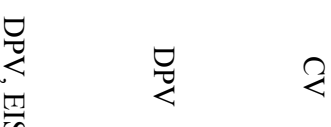

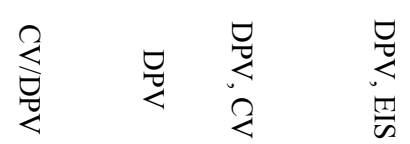

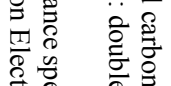

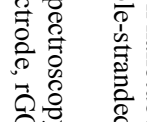

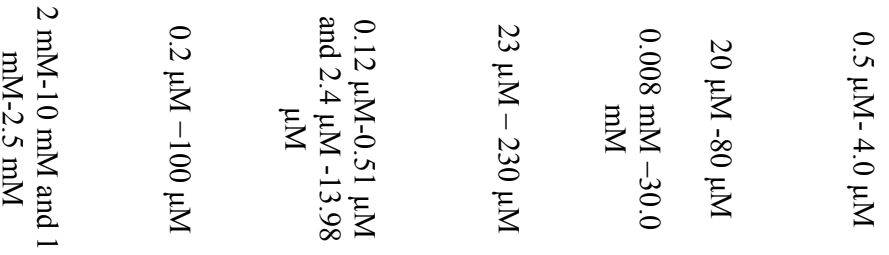

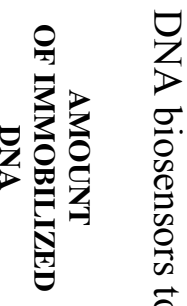




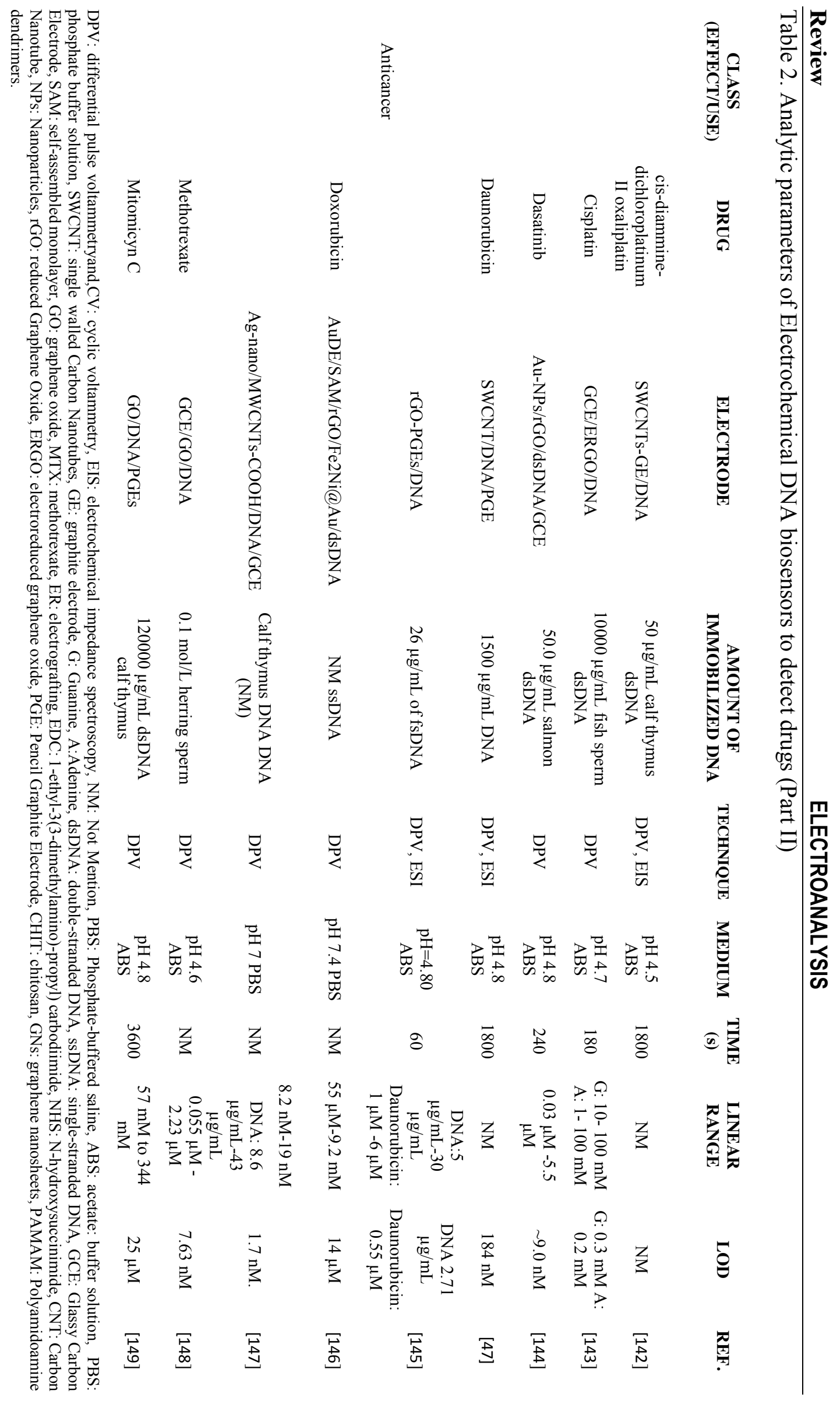




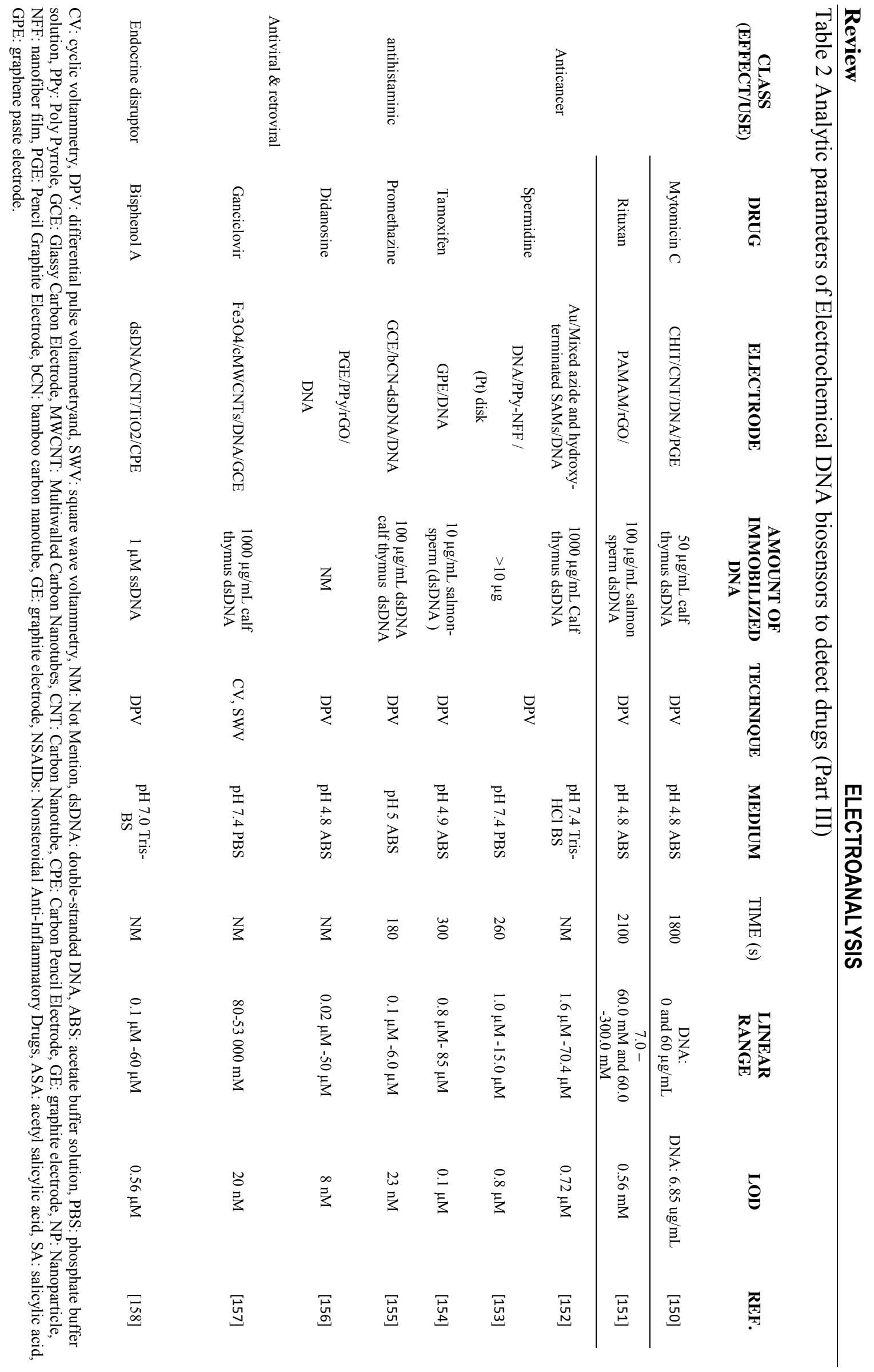




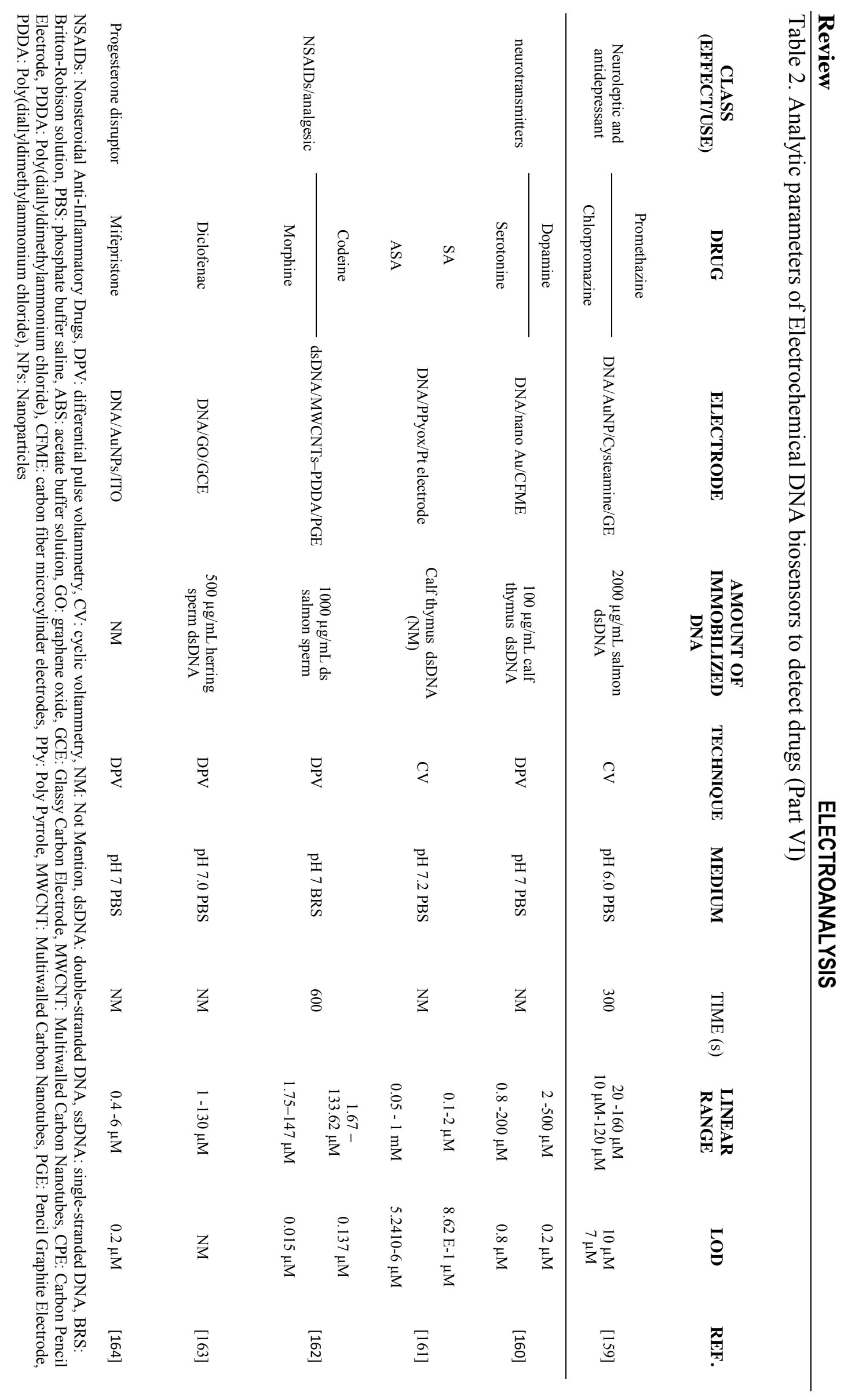




\section{Conclusions}

This review summarizes the recent advances in the application of nanomaterials for the detection of drugDNA interactions using electrochemical techniques. Electrochemical techniques such as DPV and CV are the most commonly used to evaluate the interaction in spite of the high sensitivity and simplicity. These types of analysis are based on the changes in the peak current and peak potential of DNA signal: positive shifts of the peak potential were observed in the binding via hydrophobic interactions, while electrostatic interactions led to negative shifts. By doing so, a first approach to know the possible mechanism of action of new pharmaceuticals with nucleic acids even when electroactivity of the drug is not present may be offered. However, the results obtained must be clarified with further structural techniques. The main interest is given to anticancer drugs; despite the huge advance in the field, there are still challenges to explore, which include other compounds that interact with DNA. Much effort has been made to accomplish the synthesis of new nanomaterials with unique structures and properties and apply these in DNA related biosensing systems. Sophisticated detection systems have been used to provide high selectivity and sensitivity of detection of different kinds of DNA lesions, complexes with drugs or other potentially harmful compounds. Moreover, scientist have found useful to correlate the decrease or increase in the current of the DNA with the amount of drug present in the solution, finding indirect ways to quantify nanomolar amounts of drugs in real samples such as serum, urine and plasma, as demonstrated by a number of reports and reviews published over the past two decades.

The major advantages of the nanomaterials-based DNA sensors are improvements of the sensitivity in addition to the offering of new detection alternatives being these even cost-efficient (given the small amount of the materials used). Based on the significant progress in applications of modern detection platforms employing nanotechnologies coupled to electrochemical techniques, we believe that these sensors show great promise for the future of pharmaceutical fields, including quantification, either in quality control of pharmaceuticals or testing to speed up drug discovery and drug approval processes.

\section{Acknowledgements}

Authors were honored to write this invited review in memory and recognition of Prof. Palecek contribution in the field of DNA electrochemistry. A.M. could know Prof. Palecek in person in several meetings and always has been fascinated by the great inspiring scientist and person.
The ICN2 is funded by the CERCA programme / Generalitat de Catalunya. ICN2 acknowledges the support of the Spanish MINECO for the Project MAT2017-87202$\mathrm{P}$ and through the Severo Ochoa Centers of Excellence Program under Grant SEV2201320295. KDCM thank the CONACyT for the support through the scholarship \#817447.

\section{References}

[1] T.I. Abdullin, I.I. Nikitina, O.V. Bondar'. Russ. J. Electrochem. 2008, 44, 1345-1349.

[2] V.C. Diculescu, A-M Chiorcea-Paquim, A.M. Oliveira-Brett. TrAC Trends Anal. Chem. 2016, 79, 2336.

[3] F. Kuralay, A. Erdem. The Analyst. 2015, 140, 28762880.

[4] M. Muti, M. Muti. Talanta. 2018, 178, 1033-1039.

[5] M. Hasanzadeh, N. Shadjou. Mater Sci. Eng. C. 2016, 61, 1002-1017.

[6] S. Kurbanoglu, B. Dogan-Topal, E.P. Rodríguez, B. Bozal-Palabiyik, S.A. Ozkan, B. Uslu J. Electroanal. Chem. 2016, 775, 8-26.

[7] V. González-Ruiz, A.I. Olives, M.A. Martín, P. Ribelles, M.T. Ramos, J.C. Menéndez. Biomedical engineering, trends, research and technologies., 1st. ed. (Eds. Dr. Sylwia Olsztynska), Madrid, InTech, 2011, pp. 65-90

[8] A. Hájková, J. Barek, V. Vyskočil. Bioelectrochemistry. 2017, 116, 1-9.

[9] C. Yokoyama, Y. Sueyoshi, M. Ema, Y. Mori, K. Takaishi, Hisatomi H. Oncol. Lett. 2017, 14, 6066-6070.

[10] D.G. Deavall, E.A. Martin, J.M. Horner, R. Roberts. J. Toxicol. 2012, 1-13.

[11] S. Banerjee, J. Ghosh, Biochem. Anal. Biochem. 2016, 5, 1-11.

[12] E. Arzum, O. Mehmet. Electroanalysis. 2002, 14, 965-74.

[13] K. Nakamoto, M. Tsuboi, G.D. Strahan. Drug-DNA interactions: structures and spectra. John Wiley \& Sons, Hoboken, N.Y., 2008, pp. 370.

[14] L.R. Ferguson, W.A. Denny. Mutat. Res. Mol. Mech. Mutagen. 2007, 623, 14-23.

[15] D-L. Ma, DS-H. Chan, P. Lee, MH-T. Kwan, Leung C-H. Biochimie. 2011, 93, 1252-1266.

[16] S.U. Rehman, T. Sarwar, MA. Husain, HM. Ishqi, M. Tabish. Arch. Biochem. Biophys. 2015, 576, 49-60.

[17] J. Feigon, D.E. Gilbert. Curr. Opin. Struct. Biol. 1991, $1,439-445$.

[18] M. Sirajuddin, S. Ali, A. Badshah. J. Photochem. Photobiol. B. 2013,124,1-19.

[19] WA. Denny. Curr. Med. Chem. 2001, 5, 533-544.

[20] M. Dizdaroglu. Mutat. Res. Mutat. Res. 2015, 763, $212-45$. 
[21] R. Martínez-Espinosa, R. Argüello-García, E. Saavedra, G. Ortega-Pierres. Front. Microbiol. 2015, 6, 114.

[22] D. Cappetta, A. De Angelis, L. Sapio, L. Prezioso, M. Illiano, F. Quaini, F. Rossi, L. Berrino, S. Naviglio, K. Urbanek. Oxid. Med. Cell Longev. 2017, 2017, 1-13.

[23] X. Wang, Q. Wu, A. Liu, A. Anadón, J-L. Rodríguez,M-R. Martínez-Larrañaga, Z. Yuan, M-A. Martínez. Drug Metab. Rev. 2017, 49, 395-437.

[24] M. Wanunu, S. Bhattacharya, Y. Xie, Y. Tor, A. Aksimentiev, M. Drndic. ACS Nano. 2011, 27, 9345-53. [25] EE. Ferapontova. Annu. Rev. Anal. Chem. 2018, 11, 197-218.

[26] TG. Drummond, MG. Hill, JK. Barton. Nat. Biotechnol. 2003, 21, 1192-1199.

[27] E. Paleček. Talanta. 2002, 56, 809-819.

[28] J. Wang. Anal. Chim. Acta. 2002, 469, 63-71.

[29] J. Labuda, AM. Oliveira-Brett, G. Evtugyn G, M. Fojta, M. Mascini, M. Ozsoz, I. Palchetti, E. Paleček, J. Wang. Pure Appl. Chem. 2010, 82, 1161-1187.

[30] J. Wang. Analytical Electochemistry, 2nd ed. WileyVCH, New York, 2000, pp. 60-98.

[31] N. Arshad, SI. Farooqi. Appl. Biochem. Biotechnol. 2018, 186, 1090-110.

[32] M. Sadeghi, M. Bayat, S. Cheraghi S, K. Yari, R. Heydari, S. Dehdashtian, M. Shamsipur. Luminescence. 2016, 31, 108-17.

[33] MS. Ibrahim. Anal. Chim. Acta. 2001, 443, 63-72.

[34] PK. Brahman, RA. Dar, KS. Pitre. Arab. J. Chem. 2016, 9, S1884-S1888.

[35] F. Perveen, R. Qureshi, FL. Ansari, S. Kalsoom, S. Ahmed. J. Mol. Struct. 2011, 1004, 67-73.

[36] NH. Moghadam, S. Salehzadeh, N. Shahabadi. Nucleosides Nucleotides Nucleic Acids. 2017, 1-18.

[37] K. Morawska, T. Popławski, W. Ciesielski, S. Smarzewska. Bioelectrochemistry. 2018, 123, 227-32.

[38] G. Congur, A. Erdem, F. Mese. Bioelectrochem.. 2015, 102, 21-8.

[39] GA. Tığ, B. Zeybek, Ş. Pekyardımcı. Talanta. 2016, $154,312-21$.

[40] S. Bi, H. Zhou, J. Wu, Y. Wang. J. Biomol. Struct. Dyn. 2018, 36, 1154-60.

[41] E. Kanat, E. Eksin, B. Karacicek, Y. Eraç, A. Erdem. Electroanalysis. 2018, 30, 1566-74.

[42] VR. Preedy. Neuropathology of drug addictions and substance misuse.1st ed., Vol. 3, Elsevier, London, 2016, pp. 1066.

[43] V. Mirceski, R. Gulaboski, M. Lovric, I. Bogeski, R. Kappl, M. Hoth. Electroanalysis. 2013, 25, 2411-22.

[44] Z. Altintas. Biosensors and nanotechnology: applications in health care diagnostics. 1st ed. Wiley, Hoboken, 2018, pp. 3-13.

[45] AM. Nowicka, A. Kowalczyk, S. Sek, Z. Stojek. Anal. Chem. 2013, 85, 355-61.
[46] A. Erdem, G. Congur. Int. J. Biol. Macromol. 2013, 61, 295-301.

[47] A. Erdem, H. Karadeniz, A. Caliskan. Electroanalysis. 2009, 21, 464-71.

[48] C-Z. Li, Y. Liu, JHT. Luong. Anal. Chem. 2005, 77, 478-85.

[49] S. Hasoň, J. Dvorák, F. Jelen, V. Vetterl. Crit. Rev. Anal. Chem. 2002, 32, 167-79.

[50] M. Top, O. Er, G. Congur, A. Erdem, FY. Lambrecht. Talanta. 2016, 160, 157-63.

[51] D. Koyuncu Zeybek, B. Demir, B. Zeybek, Ş. Pekyardımc1. Talanta. 2015, 144, 793-800.

[52] S. Huang, F. Zhu, Q. Xiao, Y. Liang, Q. Zhou, W. Su. RSC Adv. 2015, 5, 42889-42902.

[53] R. Hajian, Z. Tayebi, N. Shams. J. Pharm. Anal. 2017, 7, 27-33.

[54] Î. Wîlner. Bioelectronics: from theory to applications. Weinheim, Wiley-VCH, 2005. pp. 475.

[55] MM. Aleksić, V. Kapetanović. Acta Chim. Slov. 2014, 61, 555-573.

[56] L. Lu, L. Guo, T. Kang, S. Cheng. Microchim. Acta. 2017,184, 2949-57.

[57] B. Rafique, M. Iqbal, T. Mehmood, MA. Shaheen. Sens Rev. 2019, 39, 34-50.

[58] R. Hu, X-B. Zhang, R-M. Kong, X-H. Zhao, J. Jiang, W. Tan. J. Mater. Chem. 2011, 21, 16323.

[59] KM. Abu-Salah, AA. Ansari, SA. Alrokayan. J. Biomed. Biotechnol. 2010, 2010, 1-15.

[60] S. Rauf, JJ. Gooding, K. Akhtar, MA. Ghauri, M. Rahman, MA. Anwar, AM. Khalid. J. Pharm. Biomed. Anal. 2005, 37, 205-17.

[61] M. Pumera. Mater. Today. 2011, 14, 308-315.

[62] Lord H, Kelley SO. J Mater Chem. 2009, 19, 31273134.

[63] BS. Murty, P. Shankar, B. Raj, BB. Rath, J. Murday. Textbook of Nanoscience and Nanotechnology. Heidelberg, Springer, 2013, pp. 1-36.

[64] L. Zhang, L. Wang, Z.Jiang, Z.Xie. Nanoscale Res. Lett. 2012, 7, 312-

[65] Nanotechnology research publications. Statistics and Analysis. StatNano. 2017,1-32

[66] G. Alarcón-Angeles, M. Palomar-Pardavé M, A. Merkoçi. Electroanalysis. 2018, 30, 1271-80.

[67] N. Karak. Nanomaterials and Polymer Nanocomposites. Elsevier; 2019, 1-5.

[68] C. de Mello Donegá. Nanoparticles. Heidelberg, Springer, 2014, pp.1-53.

[69] S Agnihotria, S Mukherjiabc, S. Mukherji. RSC Adv., 2014, 4, 3974-3983.

[70] J. Jeevanandam, A. Barhoum, YS. Chan, A. Dufresne, MK. Danquah, R. Beilstein. J. Nanotechnol. 2018, 9, 1050-74.

[71] M. I. Katsnelson, Materialstoday, 2007, 10, 20-27 
[72] C. Li, J. Adamcik, Mezzenga R. Nat Nanotechnol. 2012;7:421

[73] AC. Power, B. Gorey, S. Chandra, J. Chapman. J. Nanotechnol. Rev. 2018, 7, 19-41.

[74] Y. Manawi, Ihsanullah, A. Samara, T. Al-Ansari, M. Atieh. Materials. 2018, 11, 822.

[75] A Gokarna, R Parize, Kadiri H, K Nomenyo, G Patriarche, Miska P, Lerondel G. RSC Adv. 2014; 4, 47234-47239.

[76] J. Zhou, Y.Ding, S-Z. Deng, L. Gong, N S. Xu, Z. L. Wang, Adv. Mater. 2005, 17, 2107-2110.

[77] J. Njuguna, F. Ansari, S. Sachse, H. Zhu, VM. Rodriguez. Health and Environmental Safety of Nanomaterials, 1st ed., Elsevier, 2014, pp. 3-27.

[78] RK. Chakrabarty, H. Moosmüller, MA. Garro, W. Patrick Arnott, JG. Slowik, ES. Cross, J-H. Hanf, P. Davidovitsf, T-B. Onaschg, R-D. Worsnopg. J. Aerosol. Sci. 2008, 39, 785-792.

[79] V. Castagnola, J. Cookman, JM. de Araújo, E. Polo, Q. Cai, CP. Silveira, Z. Krpetic, Y. Yan, L. Boselli, K. A. Dawson. Nanoscale Horiz. 2017, 2, 187-198.

[80] CR. Martin, DT. Mitchell. Anal. Chem. 1998, 70, 322A-327A.

[81] PM. Visakh, MJ. Martínez Morlanes. Nanomaterials and nanocomposites: zero- to three-dimensional materials and their composites. Weinheim, Wiley-VCH, 2016. pp. 433.

[82] CC. Koch. Nanostructured materials: processing, properties and applications. 2nd ed., William Andrew; 2006, pp. 4-46.

[83] Y-P. Wu, Y-Q Wang, H-F. Zhang, Y-Z. Wang, D-S. $\mathrm{Yu}$, L-Q. Zhang, et al. Compos Sci Technol. 2005, 65, 1195-1202.

[84] RC. Pleus, V. Murashov. Physicochemical properties of nanomaterials. Singapore, Pan Stanford Publishing, 2018, pp. 337-340.

[85] R. Tantra R. Nanomaterial characterization: an introduction. Hoboken, Wiley, 2016, pp. 294.

[86] JZ. Zhang. Optical properties and spectroscopy of nanomaterials. Hackensack, World Scientific, 2009, pp. 383.

[87] B. Nagar, M. Balsells, A. de la Escosura-Muñiz, P. Gomez-Romero, A. Merkoçi. Biosens. Bioelectron. 2019, 129, 238-244.

[88] A. Merkoçi. Biosens. Bioelectron. 2010, 26, 1164 1177.

[89] L. Baptista-Pires, A. de la Escosura-Muñiz, M. Balsells, JC. Zuaznabar-Gardona, A. Merkoçi. Electrochem. Commun. 2019, 98, 6-9.

[90] A. Merkoçi. FEBS J. 2007,274, 310-316.

[91] D. Quesada-González, A. Merkoçi. Chem. Soc. Rev. 2018, 47, 4697-709.

[92] BD. Malhotra, MA. Ali. Nanomaterials for Biosensors. Elsevier; 2018, pp. 1-74.
[93] E. Morales- Narváez, A. Merkoçi. Adv. Mater. 2018, $1-12$.

[94] L. Baptista-Pires, J. Orozco, P. Guardia, A. Merkoçi. Small. 2018, 14, 1-8.

[95] KJ. Odenthal, JJ. Gooding. The Analyst. 2007,132,603-610.

[96] V. Kavita. J. Bioeng. Biomed. Sci. 2017, 7, 1-5.

[97] A. Samanta, IL. Medintz. Nanoscale. 2016, 8, 90379095.

[98] A. Merkoçi. Biosensing using nanomaterials. Hoboken, Wiley, 2009. pp. 499.

[99] M. Holzinger, A. Le Goff, S. Cosnier. Front. Chem. 2014, 2, 1-10.

[100] C. Gao, Z. Guo, J-H. Liu, X-J. Huang. Nanoscale. 2012, 4, 1948-1963.

[101] O. Erol, I. Uyan, M. Hatip, C. Yilmaz, AB. Tekinay, MO. Guler. Nanomedicine Nanotechnol. Biol. Med. 2018, 14, 2433-2454.

[102] PA. Rasheed, N. Sandhyarani. Biosens. Bioelectron. 2017, 97, 226-237.

[103] O. Akhavan, E. Ghaderi, R. Rahighi. ACS Nano. 2012, 6, 2904-2916.

[104] H. Ma, D. Wu, Z. Cui, Y. Li, Y. Zhang, B. Du, Q. Wei. Anal. Lett. 2013, 46, 1-17.

[105] M. Wu, R. Kempaiah, P-JJ Huang, V. Maheshwari, J. Liu. Langmuir. 2011, 27, 2731-2738.

[106] B. Pérez-López, A. Merkoçi. Microchim. Acta. 2012, 179, 1-16.

[107] T. Zhang, J. Liu, C. Wang, X. Leng, Y. Xiao, L. Fu. Biosens. Bioelectron. 2017, 89, 28-42.

[108] C. Lu, P-JJ. Huang, B. Liu, Y. Ying, J. Liu. Langmuir. 2016, 32, 10776-10783.

[109] K. Saha, SS. Agasti SS, C. Kim, X. Li, VM. Rotello. Chem. Rev. 2012,112, 2739-2779.

[110] NC. Tansil, Z. Gao. Nano Today. 2006, 1, 28-37.

[111] A. de la Escosura-Muñiz, A. Merkoçi. Nucleic Acid Nanotechnology. 1st ed. (Eds. J. Kjems, E. Ferapontova, KV. Gothelf). Heidelberg, Springer, 2014, pp. 305-332.

[112] PA. Rasheed, N. Sandhyarani. Microchim. Acta. 2017, 184, 981-1000.

[113] L. Ding, AM. Bond, J. Zhai, J. Zhang. Anal. Chim. Acta. 2013, 797, 1-12.

[114] S. Zeng, K-T. Yong, I. Roy, X-Q. Dinh, X. Yu, F. Luan. Plasmonics. 2011, 6, 491-506.

[115] CM. Lieber, F. Patolsky. Materials Today. 2005,2029.

[116] S-M. Chen, U. Yogeswaran. Sensors. 2008, 8, 290313.

[117] B. He B, TJ. Morrow, CD. Keating. Curr. Opin. Chem. Biol. 2008, 12, 522-528.

[118] ASH. Makhlouf, I. Tiginyanu. Nanocoatings and ultra-thin films: technologies and applications. Oxford, Woodhead Publishing, 2011, pp. 428. 
[119] VR. Sastri. Plastics in medical devices: properties, requirements and applications. 1. ed. Amsterdam, Elsevier/William Andrew, 2010. pp. 271.

[120] L. Zhu, L. Luo, Z. Wang. Biosens. Bioelectron. 2012, 35, 507-511.

[121] J. Xu, Y. Wang, S. Hu. Microchim. Acta. 2017, 184, $1-44$.

[122] Q. Wang, J. Lei, S. Deng, L. Zhang, H. Ju. Chem. Commun. 2013, 49, 916-918.

[123] A. Singh, G. Sinsinbar, M. Choudhary, V. Kumar, R. Pasricha, HN, Verma, S-P. Singh, K. Arora. Sens. Actuators B. Chem. 2013, 185, 675-84.

[124] S. Radhakrishnan, C. Sumathi, A. Umar, S. Jae Kim, J. Wilson, V. Dharuman. Biosens. Bioelectron. 2013, 47, 133-140.

[125] Q. Wang, F. Gao, X. Zhang, B. Zhang, S. Li, Z. Hu, F. Gao. Electrochim. Acta. 2012, 62, 250-255.

[126] G. Dovbeshko, O. Repnytska, E. Obraztsova, Y. Shtogun. Chem. Phys. Lett. 2003, 372, 432-437.

[127] NS. Green, ML. Norton. Anal. Chim. Acta. 2015, $853,127-142$.

[128] M. Song, C. Pan, J. Li, X. Wang, Z. Gu. Electroanalysis. 2006, 18, 1995-2000.

[129] M. Song, X. Wang. Electrochem. Solid-State Lett. 2007, 10, F9-F12.

[130] JT. Robinson, FK. Perkins, ES. Snow, Z. Wei, PE. Sheehan. Nano Lett. 2008, 8, 3137-3140.

[131] SS. Low, H-S. Loh, JS. Boey, PS. Khiew, WS. Chiu, MTT. Tan. Biosens. Bioelectron. 2017, 94, 365-373.

[132] C. Zhu, G. Yang, H. Li, D. Du, Y. Lin. Anal. Chem. 2015, 87, 230-349.

[133] E. de Souza Gil, G. Rodriges-Melo. Braz. J. Pharm. Sci. 2010, 46, 375-391.

[134] X. Lin, Y. Ni, X. Pei, S. Kokot. Anal. Methods. 2017, 9, 1105-1111.

[135] J. Wang, Y. Li, C. Li, X. Zeng, W. Tang, X. Chen. Microchim. Acta. 2017, 184, 2999-3006.

[136] S. Cheraghi, MA. Taher, H. Karimi-Maleh, E. Faghih-Mirzaei. New J. Chem. 2017, 41, 4985-4989.

[137] PK. Brahman, RA. Dar, S. Tiwari, KS. Pitre. Rev. Anal. Chem. 2012, 31, S1884-S1888.

[138] L. Fotouhi, AB. Hashkavayi, MM. Heravi. Int. J. Biol. Macromol. 2013, 53, 101-106.

[139] H. Karimi-Maleh, F. Tahernejad-Javazmi, N. Atar, ML. Yola, VK. Gupta, AA. Ensafi. Ind. Eng. Chem. Res. 2015, 54, 3634-3639.

[140] DN. Unal, E. Eksin, A. Erdem. Electroanalysis. 2017, 29, 2292-2299.

[141] H. Mahmoudi Moghaddam, H. Beitollahi, G. Dehghannoudeh, H. Forootanfar. Int. J. Electrochem. Sci. 2017,12, 9958-9971.

[142] E. Yapasan, A. Caliskan, H. Karadeniz, A. Erdem. Mater Sci. Eng. B. 2010, 169, 169-173.
[143] Y. Yardım, M. Vandeput, M. Çelebi, Z. Şentürk, JM. Kauffmann. Electroanalysis. 2017, 29, 1451-1458.

[144] F. Tahernejad-Javazmi, M. Shabani-Nooshabadi, H. Karimi-Maleh. New J. Chem. 2018, 42,16378-16383.

[145] E. Eksin, E. Zor, A. Erdem, H. Bingol. Biosens. Bioelectron. 2017, 92, 207-14.

[146] H. Ilkhani, T. Hughes, J. Li, CJ. Zhong, M. Hepel. Biosens. Bioelectron. 2016, 80, 257-64.

[147] K. Zhang, Y. Zhang. Microchim. Acta. 2010, 169, 161-165.

[148] J. Chen, B. Fu, T. Liu, Z. Yan, K. Li. Electroanalysis, 2018, 30, 288-295.

[149] A. Erdem, M. Muti, P. Papakonstantinou, E. Canavar, H. Karadeniz, G. Congur,S. Shama. The Analyst. 2012, 137, 2129-2135.

[150] PE. Canavar, E. EkşıIn, A. Erdem.Turk. J. Chem. 2015, 39, 1-12.

[151] B. Hatamluyi, Z. Es'haghi. Electroanalysis. 2018, 30, 1659-1668.

[152] A. Mehdinia, SH. Kazemi, SZ. Bathaie, A. Alizadeh, M. Shamsipur, MF. Mousavi. J. Pharm. Biomed. Anal. 2009, 49, 587-593.

[153] K. Ghanbari, SZ. Bathaie, MF. Mousavi. Biosens. Bioelectron. 2008,23, 1825-1831.

[154] HM. Moghaddam, H. Beitollahi, G. Dehghannoudeh, H. Forootanfar. J. Electrochem. Soc. 2017, 164, B372-B376.

[155] EN. Primo, MB. Oviedo, CG. Sánchez, MD. Rubianes, GA. Rivas. Bioelectrochemistry. 2014, 99, 8 16.

[156] H. Karimi-Maleh, A. Bananezhad, MR. Ganjali, P. Norouzi, A. Sadrnia. Appl. Surf. Sci. 2018, 441, 55-60.

[157] G. Paimard, MB. Gholivand, M. Shamsipur. Measurement. 2016, 77, 269-277.

[158] H. Ezoji, M. Rahimnejad. Sens. Actuators B. Chem. 2018, 274, 370-380.

[159] N. Matsuda, G. Li, C. Fan, H. Dai, Z. Qi, J. Zhong. Anal. Sci. 2003, 19, 653-657.

[160] X. Lin, W. Shuqing, L. Lu. Anal Sci. 2004,20, 11311135.

[161] M. Yousef Elahi, SZ. Bathaie, SH. Kazemi, MF. Mousavi. Anal. Biochem. 2011, 411, 176-184.

[162] AA. Ensafi, E. Heydari-Bafrooei, B. Rezaei. Biosens. Bioelectron. 2013, 41, 627-633.

[163] L. Wei, J. Borowiec, J. Zhu, J. Zhang. J. Solid State Electrochem. 2012, 16, 3817-3823.

[164] J. Xu, J-J. Zhu, Y. Zhu, K. Gu, H-Y. Chen. Anal. Lett. 2001, 34, 503-512.

[165] Y. Cai. Front. Biosci. 2007, 12, 1946-1954.

[166] R. Zhang, X. Wang, S. Gong. Electrochem. SolidState Lett. 2004, 7, J27-J28.

[167] R. Karimi Shervedani, H. Mirhosseini, M. Samiei Foroushani, M. Torabi, FR. Rahsepar, L. NorouziBarough. Bioelectrochemistry. 2018, 119, 1-9. 
[168] C. Sengiz, G. Congur, E. Eksin, A. Erdem. Electroanalysis. 2015, 27, 1855-1863.

[169] Z. Bagheryan, J. Raoof, R. Ojani. Bioelectrochemistry. 2016, 107, 25-29.

[170] H. Beitollahi, G. Dehghannoudeh, HM. Moghaddam, H. Forootanfar. J. Electrochem. Soc. 2017, 164, H812-H817.

[171] E. Eksin, H. Karadeniz, A. Erdem. Curr. Bionanotechnol. 2015, 1, 32-36.

[172] PK. Brahman, RA. Dar, KS. Pitre. J. Saudi. Chem. Soc. 2016, 20, S236-S240 